\title{
Optimisation technique for improving wind downscaling results by estimating roughness parameters
}

\author{
Gustavo Montero $^{\mathrm{a}}$, Eduardo Rodríguez ${ }^{\mathrm{a}}$, Albert Oliver ${ }^{\mathrm{a}}$, Javier Calvo $^{\mathrm{b}}$, \\ José M. Escobar ${ }^{\mathrm{a}}$, Rafael Montenegro ${ }^{\mathrm{a}}$
${ }^{a}$ University Institute for Intelligent Systems and Numerical Applications in Engineering, SIANI, University of Las Palmas de Gran Canaria, ULPGC, Campus Universitario de Tafira, 35017, Las Palmas de Gran Canaria, Spain
http: //www. dca. iusiani.ulpgc. es/proyecto2015-2017
${ }^{b}$ Agencia Estatal de Meteorología, AEMET, Leonardo Prieto Castro, 8, 28040 Madrid, Spain

\begin{abstract}
The characterisation of the aerodynamic roughness length $\left(z_{0}\right)$ and the displacement height $(d)$ is critical when modelling the wind field using the log vertical profile. It is known that the values of these parameters depend on land coverage and weather conditions. Thus, many authors have studied their relationship, providing typical values for each land cover. In this paper, we have performed a comprehensive literature review to collect the intervals of $z_{0}$ and $d$ values for each land coverage. Using these intervals, we estimate their values using an optimisation technique that improves the results of a downscaling wind model. The downscaling model is a 3D adaptive, mass-consistent finite element model (Wind3D) that takes values from the HARMONIE-AROME or ECMWF mesoscale numerical weather prediction models. The optimisation is carried out by a memetic algorithm that combines the Differential Evolution method, a rebirth operator and the L-BFGS-B algorithm. The fitness function to be minimised is the root mean square error (RMSE) against observed wind data. This fast procedure allows updating the aerodynamic parameters for any weather condition. Numerical experiments have been carried out to show the performance of the methodology.
\end{abstract}

Keywords: ALADIN-HIRLAM HARMONIE-AROME Model,

Email addresses: gustavo.montero@ulpgc.es (Gustavo Montero), eduardo.rodriguez@ulpgc.es (Eduardo Rodríguez), albert.oliver@ulpgc.es (Albert Oliver), fcalvos@aemet.es (Javier Calvo), josem.escobar@ulpgc.es (José M. Escobar), rafael.montenegro@ulpgc.es (Rafael Montenegro) 
ECMWF Model, Wind3D, Roughness Length, Displacement Height, Downscaling Wind Field Models, Evolutionary Algorithms, Land Cover

\section{Introduction}

The influence of aerodynamic parameters in the modelling of wind field in the microscale and mesoscale, specially the wind velocity near the ground, is well known $[1,2,3]$. Therefore, the accuracy of these parameters is critical to simulate the wind field used in wind power plants energy prediction, dispersion of air pollution, and wildland fire spread among others. In this paper we propose a strategy to improve the results of a downscaling wind model by estimating the values of the roughness length $\left(z_{0}\right)$ and displacement height $(d)$ using Differential Evolution (DE) and a rebirth operator (RO).

A downscaling wind model uses the prediction of a Numerical Weather Prediction (NWP) model as input wind field to compute a new one in a higher resolution mesh that better captures the terrain features. In this paper, the downscaling wind model is Wind3D [4, 5, 6, 7], a diagnostic mass-consistent wind model, coupled with two different NWP models; specifically the European Centre for Medium-Range Weather Forecasts (ECMWF) model [8] and the HARMONIE-AROME model [9].

Diagnostic models apply conservation of mass, momentum, and energy singularly or fully, considering the terrain effects on an initial flow field. Although these models are used to obtain wind fields at a given time, the results usually represent winds of a time-averaged period. They are limited in comparison with prognostic models because they don't take into account the transient and thermal effects so they cannot simulate the evolution of the boundary layer; however, the computational requirements of the former are much lower than the latter. Diagnostic models can be classified into three different categories according to the conservation laws applied. The first category comprises the diagnostic models that are based only on the conservation of mass; see, e.g., [10, 5, 11]. Massconsistent models have been applied to the dynamical-downscaling of NWP models for local and regional scale wind forecasting, e.g., the WindNinja model [12]. The second category considers a linearised momentum equation [13, 14]; its computational cost is comparable to mass-consistent models with similar re- 
sults $[15,16]$. Nevertheless, mass-consistent models are better suited for some atmospheric dispersion problems where a fast response is required [17]. The third type of diagnostic model applies conservation of both mass and momentum to some form of turbulence closure [18, 19, 20,21], and even conservation of energy [22]. The RANS RNG $k-\varepsilon$ turbulence model has handled non-linear flow effects better than mass-consistent models [21] but it is computationally more expensive. The diagnostic model used in this paper is a new version of Wind3D, with an updated atmospheric parameterisation and wind profile proposed in $[23,24,25]$. Under this new profile, both $z_{0}$ and $d$ determine the effect of the terrain on the near-surface airflow [26], therefore it is important to have land use data available. In the last twenty-five years several projects on land cover mapping have been developed mainly using satellite images. In this paper we have used the land cover database of Spain (SIOSE) [27].

For each land cover, the actual values of $z_{0}$ and $d$ can be computed using, as a rule of thumb, a ratio of the height of the surface morphology characteristics (h). For instance, for a crop or forest canopy, Brutsaert [28] proposes a value of $d$ between $0.67 h$ and $0.75 h$, and a value of $z_{0}$ about $0.12 h$. However, this approach does not hold for non-homogeneous surfaces and a more detailed analysis is required [29]. Different authors have carried out this analysis resulting in diverse values of $z_{0}$ and $d$ for the same land cover. For this reason, we have performed a literature review to construct a table with all the ranges for each land coverage in the SIOSE database.

In addition, the values of $z_{0}$ and $d$ can be affected by land coverage variations, wind speed and direction, and atmospheric stability [30]. So, the values of $z_{0}$ and $d$ have to be known for each weather condition and a general value for each land coverage is not enough to predict the wind field reliably.

To this end, we propose an optimisation algorithm to estimate the values of the aerodynamic parameters for a downscaling wind model. This strategy has been applied to a particular region (Canary Islands) using the SIOSE land cover database and the Wind3D downscaling wind model. We want to remark that the values of $z_{0}$ and $d$ obtained in the numerical experiments are not representative values for a given land cover; they only represent the optimal solution compared to the available wind measurements for the land covers in 
the domain of interest. However, the general methodology can be applied to any combination of regions, databases, and downscaling wind models. So, the final aim of the proposed strategy is to improve the results of a downscaling wind model by estimating the optimum aerodynamic parameters values.

The content of the paper is organised following the steps of DE. This algorithm generates a random population from the ranges of $z_{0}$ and $d$ for a given point. So, as a first step, we need to know the different land covers of our region that, in this case, are given by the SIOSE database described in Sect. 2. Then, we identify the possible range of values for $z_{0}$ and $d$ for each land cover; these ranges are given in the literature review performed in Sect. 3. For a given region there exists a combination of different land covers, so we need to compute the actual value of each aerodynamic parameter by using the formula presented in Sect. 4. Then, with these values and the forecast wind field of the NWP models described in Sect. 5 we simulate the resulting wind field with the Wind3D model (Sect. 6). The last step of the algorithm is to compute the fitting function (the root square mean error between the predicted and the observed wind in meteorological stations) and generate the next population of the optimisation algorithm (Sect. 7). Numerical experiments in a test problem and a realistic case in Gran Canaria Island are described in Sect. 8 and the results are discussed in Sect. 9. Finally, the conclusions of this work are summed up in Sect. 10.

\section{SIOSE land cover database}

In 1990, the first land cover database encompassing the whole national territory was constructed in Spain on a scale of $1: 100.000$. It was developed in the framework of the CORINE Land Cover (CLC) European project [31]. After successive updates in 2000, 2006 and 2012, it became Image \& CORINE Land Cover. In short, it consists of an inventory of land cover in 44 classes. The project SIOSE (Spanish acronym for Information System of Land Cover of Spain) was created in 2005 to integrate the local information available from

the Autonomous Communities and the General State Administration. Since the requirements at the Spanish national level were higher than those supplied by the European project, the SIOSE generated a new land cover database for all the country on a $1: 25.000$ scale. It was based on reference images from 
2005, with a MUM of 0.5 to 2 ha (SIOSE 2005) and a planimetric accuracy of $5 \mathrm{~m}$ or better. The project was updated in 2009 and 2011; see National Technique Team SIOSE [27]. Other important differences with the CLC are the land classification and the hierarchy levels, which are much more simplified in the CLC than in the SIOSE.

The SIOSE database consists of different basic and compound coverages. A compound coverage is made up of a combination of basic or compound coverages. Specifically, it considers eight general groups of basic coverages (Crops, Grassland, Forest, Scrubs, No Vegetation, Artificial Coverage, Wet Coverage and Water Coverage) that are further refined into forty specific classes of basic land coverage; see. e.g., [32].

\section{Roughness length and displacement height: literature review}

To obtain the appropriate values of $z_{0}$ and $d$, the search space of each one must be defined. In this section, we present a methodology to generate a table with the ranges of $z_{0}$ and $d$ values for each land coverage. Particularly, it is applied to Gran Canaria Island, but it is suitable to any other location.

To find the ranges of possible $z_{0}$ and $d$ values for each land cover, we have carried out a literature review. Table 1 summarises it, and the specific references are listed in the caption. The first and second columns show the SIOSE code and a description for each of the distinct land coverages. The third and fourth, and the fifth and sixth columns present the nominal value and the range of the parameter $z_{0}$ and $d$, respectively. When data are not available, we have used the rule of thumb to obtain the $z_{0}$ and $d$ values from the canopy height $h$; see Brutsaert [28]. Also, it is worth remarking that $d$ is assumed to be zero for all the water surfaces (ACU, AEM, AES, ALC, ALG, AMO and LAA classes). The $z_{0}$ intervals for these water bodies verify the Charnock's formula for typical wind values, i.e., any estimation of $z_{0}$ with Charnock's formula will be within the proposed ranges. In the case of hurricane force winds, the $z_{0}$ maximum range may be increased if necessary. In such case, the Charnock approach does not apply and the resistance law appears to be more accurate; see, e.g., [33].

We have searched in the literature the minimum and the maximum values of each parameter and canopy. In addition, the values most used by different 
Table 1: Nominal values and ranges of $z_{0}$ and $d$ for the land cover classes provided by SIOSE. The superindex indicates the source.

\begin{tabular}{|c|c|c|c|c|c|}
\hline Code & Land Cover & $z_{0}(\mathrm{~m})$ & $z_{0 \min }-z_{0 \max }$ & $\boldsymbol{d}(\mathrm{m})$ & $d_{\min }-d_{\max }$ \\
\hline $\mathrm{ACM}$ & Sea Cliffs & $0.05^{[35]}$ & $0.05^{[34]}-0.19^{[34]}$ & $57^{[34]}$ & $3.3^{[34]}-85^{[34]}$ \\
\hline $\mathrm{ACU}$ & Water Courses & $0.00025^{[37]}$ & $0.0001^{[38]}-0.01^{[31]}$ & $0^{[28,39]}$ & - \\
\hline AEM & Water body. Reservoirs & $0.00025^{[38]}$ & $0.0001^{[38]}-0.005^{[40]}$ & $0^{[28,39]}$ & - \\
\hline AES & Estuaries & $0.0002^{[41]}$ & $0.0001^{[38]}-0.01^{[31]}$ & $0^{[28,39]}$ & - \\
\hline ALC & Coastal Lagoons & $0.005^{[40]}$ & $0.0001^{[38]}-0.01^{[31]}$ & $0^{[28,39]}$ & - \\
\hline ALG & Water body. Lakes and Lagoons & $0.0005^{[42]}$ & $0.0001^{[38]}-0.005^{[40]}$ & $0^{[28,39]}$ & - \\
\hline $\mathrm{AMO}$ & Seas and Oceans & $0.0002^{[41]}$ & $0.0001^{[38]}-0.03^{[35]}$ & $0^{[28,39]}$ & - \\
\hline ARR & Rocky Outcrops and Rocks & $0.005^{[31]}$ & $0.0003^{[43]}-0.18^{[44]}$ & $0.03^{[28]}$ & $0^{[28]}-0.96^{[28]}$ \\
\hline $\mathrm{CCH}$ & Screes & $0.1^{[35]}$ & $0.05^{[45]}-0.15^{[46]}$ & $0.6^{[47]}$ & $0.56^{[47]}-0.66^{[47]}$ \\
\hline CLC & Quaternary lava flow & $0.0286^{[48]}$ & $0.0013^{[48]}-0.0735^{[48]}$ & $0.15^{[28]}$ & $0^{[28]}-0.4^{[28]}$ \\
\hline $\mathrm{CNF}$ & Forest. Conifers & $1.28^{[49]}$ & $0.25^{[50]}-1.93^{[51]}$ & $13.1^{[52,53]}$ & $4.87^{[51]}-22^{[47]}$ \\
\hline $\mathrm{CHA}$ & Herbaceous crops. Rice & $0.072^{[54]}$ & $0.001^{[55]}-0.11^{[54]}$ & $0.85^{[54]}$ & $0.1^{[54]}-1.55^{[54]}$ \\
\hline CHL & Herbaceous crops. Different from Rice & $0.1^{[56]}$ & $0.004^{[57]}-0.74^{[58]}$ & $0.25^{[57]}$ & $0.1^{[57]}-3^{[59]}$ \\
\hline $\mathrm{EDF}$ & Artificial Coverage. Buildings & $1.5^{[60]}$ & $0.7^{[60]}-3.7^{[58]}$ & $14^{[60]}$ & $7^{[60]}-19.73^{[28]}$ \\
\hline FDC & Forest. Leafy. Deciduous & $1^{[61]}$ & $0.18^{[61]}-1.4^{[35]}$ & $11.8^{[62]}$ & $3^{[62]}-21.6^{[62]}$ \\
\hline FDP & Forest. Leafy. Evergreen & $0.72^{[44]}$ & $0.6^{[37]}-2.65^{[63]}$ & $9.7^{[62]}$ & $3^{[62]}-31^{[60]}$ \\
\hline
\end{tabular}


Table 1: Continued

\begin{tabular}{|c|c|c|c|c|c|}
\hline Code & Land Cover & $z_{0}(m)$ & $z_{0 \min }-z_{0 \max }$ & $d(m)$ & $d_{\min }-d_{\max }$ \\
\hline GNP & No Vegetation. Glaciers and Perpetual Snow & $0.001^{[31]}$ & $0.00001^{[64]}-0.012^{[60]}$ & $0.01^{[28]}$ & $0^{[28]}-0.06^{[28]}$ \\
\hline HMA & Salt Marshes & $0.11^{[44]}$ & $0.0002^{[43]}-0.17^{[43]}$ & $0.6^{[28]}$ & $0^{[28]}-0.93^{[28]}$ \\
\hline HPA & Wetlands & $0.1^{[31]}$ & $0.005^{[61]}-0.55^{[44]}$ & $0.55^{[28]}$ & $0.03^{[28]}-3^{[28]}$ \\
\hline HSA & Continental Salt Mines & $0.01^{[31]}$ & $0.0005^{[31]}-0.04^{[40]}$ & $0.05^{[28]}$ & $0^{[28]}-0.22^{[28]}$ \\
\hline HSM & Salt Lakes & $0.01^{[31]}$ & $0.0005^{[31]}-0.04^{[40]}$ & $0.05^{[28]}$ & $0^{[28]}-0.22^{[28]}$ \\
\hline HTU & Peat bogs & $0.03^{[31]}$ & $0.0005^{[31]}-0.03^{[31]}$ & $0.16^{[28]}$ & $0^{[28]}-0.16^{[28]}$ \\
\hline LAA & Artificial Coverage. Artificial water body & $0.0001^{[31]}$ & $0.0001^{[31]}-0.005^{[40]}$ & $0^{[31,39]}$ & - \\
\hline $\mathrm{LFC}$ & Woody Crops. Citrus Fruit Trees & $0.31^{[65]}$ & $0.03^{[38]}-0.4^{[66]}$ & $3^{[47]}$ & $0^{[59]}-4^{[59]}$ \\
\hline LFN & Woody Crops. No Citrus Fruit Trees & $0.25^{[31]}$ & $0.03^{[38]}-1^{[67]}$ & $0.92^{[68]}$ & $0^{[59]}-4^{[59]}$ \\
\hline LOC & Other Woody Crops & $0.0615^{[28,36]}$ & $0.0369^{[28,36]}-0.0861^{[28,36]}$ & $0.33^{[28,36]}$ & $0.2^{[28,36]}-0.47^{[28,36]}$ \\
\hline LOL & Olive Groves & $0.48^{[69]}$ & $0.25^{[31]}-0.61^{[69]}$ & $2.67^{[69]}$ & $2^{[69]}-3^{[69]}$ \\
\hline LVI & Vineyards & $0.2^{[70]}$ & $0.08^{[71]}-0.55^{[70]}$ & $0.75^{[70]}$ & $0.31^{[71]}-1.4^{[72]}$ \\
\hline MTR & Scrubs & $0.16^{[61]}$ & $0.016^{[61]}-1^{[35]}$ & $4.8^{[73]}$ & $0.9^{[60]}-7.1^{[73]}$ \\
\hline OCT & Artificial Coverage. Other Buildings & $0.5^{[31]}$ & $0.06^{[44]}-1^{[31]}$ & $4^{[74]}$ & $2^{[74]}-14^{[60]}$ \\
\hline PDA & No Vegetation. Beaches, Dunes and Sandy Areas & $0.0003^{[31]}$ & $0.0003^{[31]}-0.06^{[43]}$ & $0^{[28]}$ & $0^{[28]}-0.33^{[28]}$ \\
\hline PRD & Crops. Meadows & $0.03^{[31]}$ & $0.001^{[64]}-0.1^{[31]}$ & $0.013^{[60]}$ & $0.007^{[59]}-0.035^{[60]}$ \\
\hline
\end{tabular}


Table 1: Continued

\begin{tabular}{|c|c|c|c|c|c|}
\hline Code & Land Cover & $z_{0}(m)$ & $z_{0 \min }-z_{0 \max }$ & $d(m)$ & $d_{\min }-d_{\max }$ \\
\hline PST & Grasslands & $0.09^{[64]}$ & $0.001^{[64]}-0.15^{[64]}$ & $0.171^{[75]}$ & $0.013^{[60]}-0.66^{[59]}$ \\
\hline $\mathrm{RMB}$ & No Vegetation. Ravines & $0.0012^{[76]}$ & $0.0003^{[38]}-0.005^{[77]}$ & $0.03^{[28,41]}$ & $0^{[28]}-0.03^{[28]}$ \\
\hline SDN & No Vegetation. Bare Soil & $0.001^{[43]}$ & $0.0002^{[77]}-0.04^{[44]}$ & $0.03^{[28,41]}$ & $0^{[28]}-0.22^{[28]}$ \\
\hline SNE & Artificial Coverage. Unbuilt Land & $0.0003^{[43]}$ & $0.0002^{[77]}-0.04^{[35]}$ & $0^{[28]}$ & $0^{[28]}-0.22^{[28]}$ \\
\hline VAP & Artificial Coverage. Road, Parking or Unvegetated Pedestrian Areas & $0.03^{[31]}$ & $0.0035^{[76]}-0.5^{[31]}$ & $1^{[39,78]}$ & $0.02^{[78]}-2.5^{[78]}$ \\
\hline $\mathrm{ZAU}$ & Artificial Coverage. Artificial Green Area and Urban Trees & $0.4^{[38]}$ & $0.03^{[43]}-1.3^{[58]}$ & $3.5^{[39,78]}$ & $3.5^{[60]}-14^{[60]}$ \\
\hline ZEV & Artificial Coverage. Extraction or Waste Areas & $0.1^{[31]}$ & $0.0003^{[43]}-0.18^{[44]}$ & $0.16^{[28,77]}$ & $0^{[28]}-1^{[28]}$ \\
\hline ZQM & No Vegetation. Burnt Areas & $0.6^{[31]}$ & $0.1^{[31]}-1.1^{[43]}$ & $3.27^{[28]}$ & $0.54^{[28]}-6^{[28]}$ \\
\hline
\end{tabular}


authors have been selected as nominal values, but these are not used in our approach. In fact, we used the ranges of Table 1 as searching space for the solution of each parameter in the characteristic wind situations shown in Table 3. Then, we performed an extended literature review on the assigned values to the roughness parameters of each coverage. For this reason, in general, we think that the proposed ranges completely cover the variation interval of $z_{0}$ and $d$ corresponding to each coverage, respectively, not only for the region studied in this paper, but also for any region if the specific coverage is included in that literature review. Nevertheless, some ranges have been defined according to the local characteristics of certain coverages. This is the case of the high sea cliffs in Gran Canaria, for example, where the range of $z_{0}$ and $d$ have been adapted to such heights. For instance, the works of Roballo and Fisch [34] and Fry et al. [35] have been employed to characterise Sea Cliffs. The former study proposes a value of $d=3.3 \mathrm{~m}$ for a cliff of $40 \mathrm{~m}$. Using this same ratio, the values for the Andén Verde $(690 \mathrm{~m})$ and the Risco de Faneque $(1027 \mathrm{~m})$ cliffs are $57 \mathrm{~m}$ and 85 $\mathrm{m}$, respectively. These values have been taken as lower bound $(3.3 \mathrm{~m})$, nominal value $(57 \mathrm{~m})$ and upper bound $(85 \mathrm{~m})$. Another case is Other Woody Crops related to Aloe Vera plantations on the island. In this case, Molero-Paredes and Matos [36] studied the typical canopy height ranges for the Aloe Vera. Using these ranges and the rule of thumb, we have obtained the $z_{0}$ and $d$ ranges and nominal values. So, in general, these are the only particular cases to review for the application of ranges given in Table 1 to any other region.

The bibliography of Table 1 may be classified according to the procedure used to obtain $z_{0}$ and $d$. Several authors proposed parameterisations of the roughness parameters from measures of the wind and other physical magnitudes. This is the case of [28] which is used here in many coverages; [38] in water surfaces; [45] in screes; [47] in screes, conifers, and citrus fruit trees; [52, 53] in conifers; [55] in rice crops; [74] in low buildings; [69] in olive groves; [71] in vineyards; [39] in water surfaces; and [78] in artificial coverages. Some other works are based on the canopy morphology, such as [40] used in water and saline coverages; [61] in deciduous forests, wetlands and scrubs; and [36] in Aloe Vera crops.

Another extended approach is the use of measurements and wind profile: [34] used in cliffs; [46] in screes; [48] in Quaternary lava flow; [49, 50, 51] in 
conifers; [54] in rice crops; [57] in crops different from rice; [68] in no citrus fruit trees; [70, 72] in vineyards; [73] in scrubs; and [77] in soils without vegetation and artificial coverages.

Also in Table 1 , there are some values of $z_{0}$ and $d$ arising from applications of specific numerical models with their land cover databases. For example, [42] used them in lakes and lagoons; [44] in rocky outcrops and rocks, evergreen forests, salt marshes, wetlands, bare soils, and artificial coverages; [63] in evergreen forests; [67] used in no citrus fruit trees; [75] in grasslands; and [76] in ravine and road, parking or unvegetated pedestrian areas.

Some papers dealing with collections of data, specially from old publications, were useful too. In particular, the one by [41] used in estuaries, seas and oceans, and soils without vegetation; [58] in crops different from rice and artificial coverage; [60] in buildings, evergreen forests, glaciers and perpetual snow, scrubs, meadows, grasslands and artificial green area and urban trees; [62] in deciduous and evergreen forests; and [59] in crops different from rice, woody crops, meadows and grasslands. Also some early publications were used for constructing Table 1, such as [56], used in crops different from rice; [64] in glaciers and perpetual snow, meadows and grasslands; and $[65,66]$ in citrus fruit trees.

Finally, some of the current land cover databases based on remote sensing surveys (specifically, aircraft lidar and satellite images) that were taken into account are [35]: the NLCD database used in cliffs; [37]: the 1-km land cover data set DISCOVER (IGBP-DIS) for water courses; [31]: the CLC database applied in many coverages; and [43]: the LGN3 database used in rocky outcrops and rocks, salt marshes, soils without vegetation, and artificial coverages.

\section{Roughness length and displacement height characterisation}

The SIOSE project uses a vectorial format, but, for convenience, we will translate it to a raster format. For this, we will define a grid with $n_{p}$ points and, for each point, we will look for the mean value of basic coverages. Once we have the values of $z_{0}$ and $d$ for each basic coverage, we can compute the specific $z_{0}$ and $d$ values at any point using an appropriate weighted mean.

This way, the SIOSE database will let us create a matrix with the percentage of the basic coverages at any point. This matrix is defined as follows: let $M$ 
be an $n_{p} \times n_{b}$ matrix, with components $m_{i, j}$, where $n_{b}$ is the number of basic coverages. For each row $i$ of $M, m_{i, j}$ is the fraction of the basic coverage $j$ at the point $n_{i}\left(m_{i, j}<1\right.$ and $\left.\sum_{j=1}^{n_{b}} m_{i, j}=1\right)$.

When the ranges of $z_{0}$ and $d$ are set for each basic land coverage, we can compute its values at any point of the terrain. Assuming that the values of $z_{0}$ and $d$ are a certain mean of the values of the basic coverages $z_{0 j}$ and $d_{j}$, $j=1, \ldots, n_{b}$, we can compute their values at any point. A simple weighted average may produce differences with the effective roughness of one order of magnitude. In this case, only the formula proposed by [79] was applied; in this approach, for a coverage $i$ composed by $n_{b}$ basic canopies with roughness length $z_{0 j} ; j=1, \ldots, n_{b}$ on a fraction $m_{i j}$ of the area, respectively, an approximation to the effective roughness length is given by computing the weighted geometric mean roughness length $z_{0}$ :

$$
z_{0}=\prod_{j=1}^{n_{b}} z_{0 j}^{m_{i j}} .
$$

The study by [80] for the effective roughness length improves the formula proposed by [79], taking into account a non-dimensional patchiness parameter to consider the textural information about the spatial dependence of the primitives (regions with specific properties) characterising the surface inhomogeneity. However, the coverage information provided by the land cover databases (e.g., SIOSE) does not include the spatial distribution of basic coverages in a composed one, but only the fraction of the area covered by each surface type.

Regarding the displacement height, $d,[80]$ and [79] did not study its estimation. In any case, equation (1) is not appropriate for $d$, since, in the case of a basic coverage with displacement height equal to zero, it would produce a mean $d=0$ independently of the $d_{j}$ values of the other basic coverages. Some other works have studied the variation of $d$ in several specific coverages, e.g., in urban [81] and vegetation [82, 83] canopies. One important conclusion is that the effective displacement height of a heterogeneous coverage can exceed the surface mean canopy height significantly. Taking this into account, we propose to use a weighted root mean square to obtain a higher mean value than Taylor's one:

$$
d=\sqrt{\sum_{j=1}^{n_{b}} m_{i j} d_{j}^{2}},
$$


where $d_{j}$ and $m_{i j}$ are the displacement height and the fraction of the basic coverage $j$ in the composed one $i$, respectively. Figures 1(a) and (b) show the resulting composed $z_{0}$ and $d$ values in Gran Canaria Island, considering the nominal values of the basic coverages given in Table 1 .

It can be noted that the application of this methodology to another database is straightforward.

\section{Mesoscale numerical weather prediction model}

The wind field model used in this work is a diagnostic model (Wind3D). To provide the model with predictive capacity, we downscaled the results from a mesoscale numerical weather prediction model. Specifically, the mesoscale models considered in this paper are the ECMWF and the HARMONIE-AROME models, as proposed in Oliver et al. [7].

The Integrated Forecasting System (IFS) is the global atmospheric model operational at ECMWF (http://www. ecmwf .int). The dynamical core is spectral, semi-implicit, 2 time-level and semi-Lagrangian. The version used in this work corresponds to the high resolution deterministic version of the model based on cy41r1 having a T1279 spectral truncation which corresponds approximately to $16 \mathrm{~km}$ horizontal resolution. Non-linear processes, physical parameterisations, water species and tracers are treated in grid point space. In the vertical it uses a finite element discretisation with 137 levels including 20 levels below $1000 \mathrm{~m}$ and model top at $1 \mathrm{hPa}$.

The HARMONIE-AROME non-hydrostatic convection permitting model is a particular configuration of the ALADIN-HIRLAM shared system resulting from the collaboration between ALADIN and HIRLAM Consortia. This configuration described in [84] is based on the AROME-France model [85].

The State Meteorological Agency of Spain (AEMET) is running HARMONIEAROME (or just HARMONIE) at $2.5 \mathrm{~km}$ horizontal grid spacing over two domains (Iberian Peninsula-Balearic Islands and the Canary Islands). The vertical discretisation includes 65 levels with 15 levels below $1000 \mathrm{~m}$ and the model top at $10 \mathrm{hPa}$. The model updates the atmospheric and surfaces variables every 3 hours using a cutoff time of 1 hour and 10 minutes for the observations. For the boundary conditions, the model is relaxed to the forecasts provided by the 
(m)

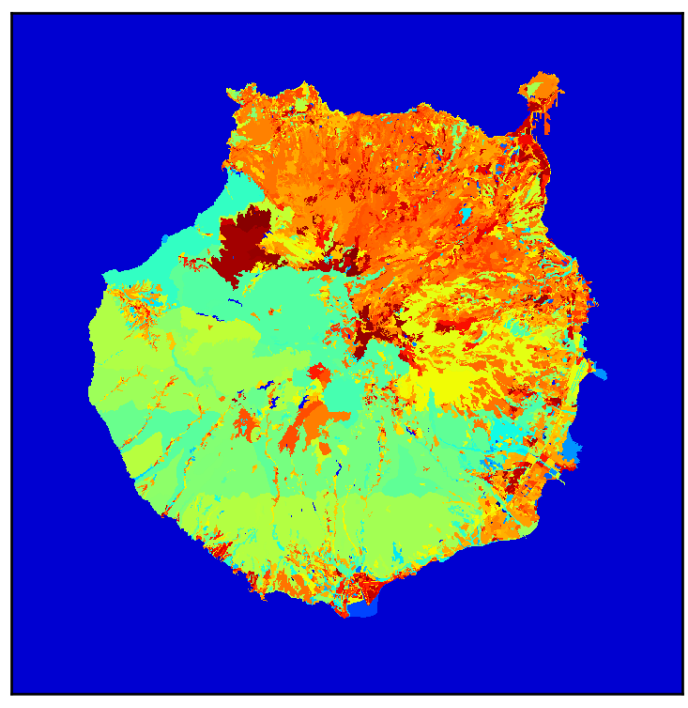

$1.15 \times 10^{0}$
$-4.93 \times 10^{-1}$
$-2.11 \times 10^{-1}$
$-9.01 \times 10^{-2}$
$-3.85 \times 10^{-2}$
$-1.64 \times 10^{-2}$
$-7.02 \times 10^{-3}$
$-3.00 \times 10^{-3}$
$-1.28 \times 10^{-3}$
$5.48 \times 10^{-4}$
$-2.34 \times 10^{-4}$
$1.00 \times 10^{-4}$

(a) Roughness length $\left(z_{0}\right)$ map

(m)
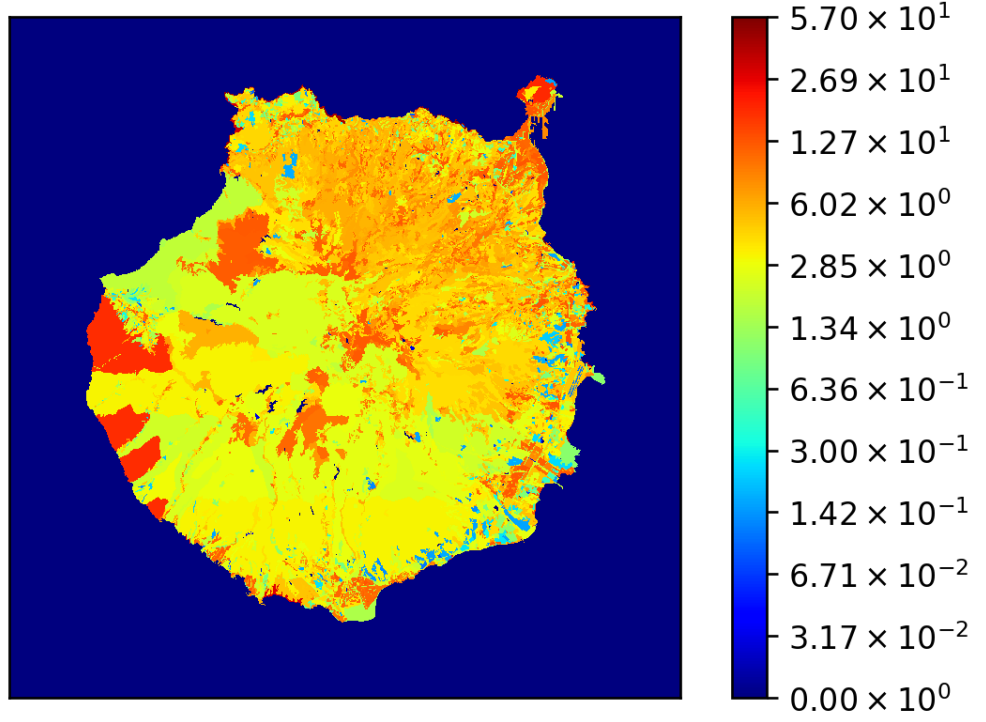

(b) Displacement height $(d)$ map

Figure 1: Roughness length and displacement height maps of Gran Canaria island $(\mathrm{m})$ corresponding to the nominal values stated in Table 1 and using the mean values given in equations (1) and (2), respectively. 
ECMWF-IFS integrations corresponding to a cycle 6 hours earlier than the Limited Area Model cycle. The HARMONIE $2.5 \mathrm{~km}$ model significantly improves local and extreme forecasts of coarser grid models like HIRLAM or ECMWF [86].

\section{Diagnostic wind model}

We consider a mass-consistent model $[10,5,6,87]$ to compute a wind field $u$ in a domain $\Omega$ with a boundary $\Gamma=\Gamma_{a} \cup \Gamma_{b}$, which satisfies the mass continuity equation in $\Omega$, for an incompressible flow, and the impermeability condition on the terrain $\Gamma_{a}$ :

$$
\begin{array}{ll}
\nabla \cdot u=0 & \text { in } \Omega, \\
n \cdot u=0 & \text { on } \Gamma_{a},
\end{array}
$$

where $n$ is the outward-pointing normal unit vector and $\Gamma_{b}$ the free boundary. The model formulates a least-squares problem in the domain $\Omega$ to find a wind field $u=\left(u_{x}, u_{y}, u_{z}\right)$, such that it is adjusted as much as possible to an interpolated wind field $u_{0}=\left(u_{0 x}, u_{0 y}, u_{0 z}\right)$. The adjusting functional for a field $v=\left(v_{x}, v_{y}, v_{z}\right)$ is defined as:

$$
e(v)=\frac{1}{2} \int_{\Omega}\left(v-u_{0}\right)^{T} P\left(v-u_{0}\right) d \Omega,
$$

where $\left(v-u_{0}\right)^{T}$ is the transpose of $\left(v-u_{0}\right), P$ is the $3 \times 3$ diagonal transmissivity matrix with $P_{1,1}=P_{2,2}=2 \alpha_{1}^{2}$ and $P_{3,3}=2 \alpha_{2}^{2}$, being $\alpha_{1}$ and $\alpha_{2}$ the Gauss Precision moduli. The Lagrange multiplier technique is used to minimise the functional (4), with the restrictions (3). Considering the Lagrange multiplier $\lambda$, the Lagrangian is defined as:

$$
L(v, \lambda)=e(v)+\int_{\Omega} \lambda \nabla \cdot v d \Omega,
$$

and the solution $u$ is obtained by finding the saddle point $(u, \psi)$ of the Lagrangian (5). This resulting wind field satisfies the Euler-Lagrange equation:

$$
u=u_{0}+P^{-1} \nabla \psi,
$$

where $\psi$ is the Lagrange multiplier. Since $\alpha_{1}$ and $\alpha_{2}$ are constant in $\Omega$ and substituting (6) in (3), the variational formulation is the following elliptic problem 
in $\psi$ :

$$
\begin{aligned}
\frac{\partial^{2} \psi}{\partial x^{2}}+\frac{\partial^{2} \psi}{\partial y^{2}}+\alpha \frac{\partial^{2} \psi}{\partial z^{2}} & =-2 \alpha_{1}^{2}\left(\frac{\partial u_{0 x}}{\partial x}+\frac{\partial u_{0 y}}{\partial y}+\frac{\partial u_{0 z}}{\partial z}\right) & & \text { in } \Omega \\
-n \cdot P^{-1} \nabla \psi & =n \cdot u_{0} & & \text { on } \Gamma_{a}, \\
\psi & =0 & & \text { on } \Gamma_{b},
\end{aligned}
$$

where $\alpha=\alpha_{1} / \alpha_{2}$ is the ratio of the Gauss Precision Moduli. To solve it, we will use the finite element method.

\subsection{Construction of the interpolated wind field}

The interpolated wind field is computed in the whole domain $\Omega$ from pointwise wind data. The wind data can come from measurement stations or a numerical weather prediction system. In this work, we will use the HARMONIEAROME forecast wind field, as proposed by Oliver et al. [7]. Using these data, we construct the interpolated wind field, $u_{0}$ in two steps: first, a horizontal interpolation and, then, a vertical extrapolation.

\subsubsection{Horizontal interpolation}

At this stage, we want to interpolate the available wind data at any point located at a height $z_{m}$ over $z_{t}+d$, where $z_{t}$ is the terrain surface height. If we have a set of dispersed data, a simple technique for this interpolation is formulated as a weighted sum of the inverse-square law and the height difference interpolation [5]:

$$
u_{0}\left(z_{m}\right)=\xi \frac{\sum_{i=1}^{n_{h}} \frac{u_{i}^{h}}{\delta_{i}^{2}}}{\sum_{i=1}^{n_{h}} \frac{1}{\delta_{i}^{2}}}+(1-\xi) \frac{\sum_{i=1}^{n_{h}} \frac{u_{i}^{h}}{\left|\Delta h_{i}\right|}}{\sum_{i=1}^{n_{h}} \frac{1}{\left|\Delta h_{i}\right|}},
$$

where the value of $u_{i}^{h}$ is the wind velocity at the point $i ; n_{h}$ is the number of available points; $\delta_{i}$ is the horizontal distance between point $i$ and the point of interest; $\left|\Delta h_{i}\right|$ is their height difference, and $\xi$ is a weighting parameter $(0 \leq$ $\xi \leq 1)$ that determines to what degree the focus is put on the inverse-square law or the height difference interpolation.

When a grid of wind data is available, e.g., HARMONIE-AROME or ECMWF wind results, it is preferable to interpolate the wind field with a simple bilinear Lagrange interpolation in the cell containing the studied point. 


\subsubsection{Vertical extrapolation}

Further than the Monin-Obukhov similarity theory, the concepts of Neutral and Stable Boundary Layers (SBL) have been revised to consider the effect of the free-flow static stability and baroclinicity on the turbulent transport of momentum and scalars in the boundary layer, as well as the model of turbulent entrainment for Convective Boundary Layers (CBL) [25]. Accordingly, different types of SBL regimes can be distinguished: truly neutral (absence of any buoyancy effects throughout the PBL); conditionally neutral (buoyancy flux at the surface is negligible); short-lived nocturnal (separated from the free atmosphere by near-neutral residual layers); and long-lived (immediately adjoining the stably stratified free atmosphere). The SBL height, $h$, may be evaluated according to the expression recently introduced by [88]. This expression represents a multi-limit equation for the equilibrium PBL height that covers the types mentioned earlier of neutral and stable conditions in the atmosphere. In contrast to the stable and neutral cases, the estimation of the CBL height is not straightforward, since our model is diagnostic and the recommended parameterisations are prognostic. To overcome this problem, some prognostic data must be used. In this approach, the CBL height is obtained from the results of the mesoscale model, e.g., HARMONIE-AROME model.

The estimation of the PBL height is calculated separately for stable/neutral conditions and convective conditions. For this, the Brunt-Väisälä frequency $N$ in the PBL and the surface buoyancy flux $B_{s}$ allow to characterise atmospheric stability:

$$
N^{2}=\frac{g}{T}\left(\frac{\partial T}{\partial z}+\Gamma_{d}\right),
$$

$g$ being the gravity acceleration, $T$ a reference value of the air absolute temperature, $z$ the height variable and $\Gamma_{d}=9.810^{-3} \mathrm{~K} / \mathrm{m}$ the dry adiabatic lapse rate. If $N^{2} \geq 0$, the atmosphere is considered stable/neutral. However, $N^{2}<0$ indicates a CBL.

In stable/neutral atmosphere (SBL), the formula to compute the SBL height was proposed by [88]:

$$
h=\gamma u_{*} / f
$$

where $u_{*}$ is the surface friction velocity, $f$ the Coriolis parameter defined as $f=$ 
$2 \omega \sin \phi$ ( $\omega$ is the angular frequency of the Earth rotation and $\phi$ the latitude), and $\gamma$ is a function of the imposed-stability parameter $\mu_{N}=N_{2 h-h} / f$ in the free atmosphere:

$$
\gamma=\gamma_{0}\left(1+\frac{\gamma_{0}^{2} C_{u N}}{C_{s}^{2}} \mu_{N}\right)^{-1 / 2}
$$

Experimental data suggest $\gamma_{0}=0.5, C_{u N} / C_{s}^{2}=0.6 ; N_{2 h-h}$ is the free-flow Brunt-Väisälä frequency in the free atmosphere immediately above the SBL $(h<z<2 h)$. In particular, the stable/neutral PBL may be classified as: truly neutral (TN) at $\mu_{N}=0\left(B_{s}\right.$ and $\left.N_{2 h-h}=0\right)$; conditionally neutral (CN) usually at $0.5 \times 10^{2}<\mu_{N}<3 \times 10^{2}\left(B_{s} \geq 0\right.$ and $\left.N_{2 h-h}>0\right)$; nocturnal stable (NS) at $\left(B_{s}<0\right.$ and $\left.N_{2 h-h}=0\right)$; and long-lived stable (LS) at $\left(B_{s}<0\right.$ and $\left.N_{2 h-h}>0\right)$.

We have implemented the log wind profile proposed in [24] for stable/neutral conditions:

$$
\begin{aligned}
& u=\frac{u_{*}}{k}\left(\ln \frac{\zeta}{\zeta_{0}}+b_{1}\left(\zeta-\zeta_{0}\right)+b_{2}\left(\zeta-\zeta_{0}\right)^{2}+b_{3}\left(\zeta-\zeta_{0}\right)^{3}\right), \\
& v=-\frac{u_{*}}{k} \delta\left(-\left(\zeta-\zeta_{0}\right) \ln \left(\zeta-\zeta_{0}\right)+a_{1}\left(\zeta-\zeta_{0}\right)+a_{2}\left(\zeta-\zeta_{0}\right)^{2}+a_{3}\left(\zeta-\zeta_{0}\right)^{3}\right),
\end{aligned}
$$

for $z>d+z_{0}$, where $u$ and $v$ are the components of the horizontal wind velocity along the $x$ and $y$ axis of a right-hand Cartesian coordinate system with the $x$-axis along the surface stress; $\zeta=(z-d) / h$ and $\zeta_{0}=z_{0} / h$ are dimensionless heights; $k \approx 0.4$ is the von Kármán constant; $\delta=f h /\left(k u_{*}\right)=$ $\gamma / k$ is the dimensionless rotation rate parameter; $a_{1}=4 / \delta^{2}+\bar{\Pi}, a_{2}=-\frac{3}{2} \bar{\Pi}$, $a_{3}=\frac{1}{3}\left(1-4 / \delta^{2}+2 \bar{\Pi}\right), b_{1}=\Pi-3, b_{2}=-\frac{3}{2} \Pi, b_{3}=\frac{2}{3}(\Pi+1)$, with $\Pi=$ $C_{R} \delta^{2}+C_{L} \frac{k h}{L}+C_{N} \frac{N h}{u_{*}}$ and $\bar{\Pi}=\bar{C}_{R} \delta^{2}+\bar{C}_{L} \frac{k h}{L}+\bar{C}_{N} \frac{N h}{u_{*}}$; and $L=-u_{*}^{3} /\left(k B_{s}\right)$ is the Monin-Obukhov length. This model uses the values of estimates of the dimensionless constants obtained by [24] on the basis of empirical and numerical (LES) data: $C_{R}=7, C_{L}=4.5, C_{N}=0.4, \bar{C}_{R}=0, \bar{C}_{L}=-7, \bar{C}_{N}=-1$. In addition, the original expression in [24] has been slightly modified to verify $u(z)=0$ and $v(z)=0$ at $z=d+z_{0}$. The vertical component $w$ of the wind velocity is assumed to be zero. From (12a), the surface friction velocity may be computed using the horizontal wind velocity interpolated at $z=z_{m}, u_{0}\left(z_{m}\right)$ :

$$
\begin{aligned}
& \ln \frac{z_{m}-d}{z_{0}} u_{*}^{3}-\left[k u_{0}\left(z_{m}\right)-\left(C_{R} \frac{\gamma}{k^{2}}+\frac{C_{N} N_{2 h-h}}{f}-\frac{3}{\gamma}\right) f\left(z_{m}-\left(d+z_{0}\right)\right)\right] u_{*}^{2} \\
& -C_{L} k^{2} B_{s}\left(z_{m}-\left(d+z_{0}\right)\right)=0
\end{aligned}
$$

where the squared and cubic terms of the wind profile were neglected at $z=z_{m}$. 
The estimation of the CBL height is provided by the mesoscale model estimations. If the ratio between the mechanical velocity scale $V_{*}=\left(2 U u_{*}\right)^{1 / 3}$ and the convective velocity scale $W_{*}=\left(B_{s} h\right)^{1 / 3}$ is negligible, i.e., $V_{*} / W_{*} \ll 1$, we have a Purely Convective Layer (PC). Otherwise, it is a Mechanically-Convective Layer (MC) [25]. The log wind profile in the CBL was given in [23] as follows:

$$
|u|= \begin{cases}\frac{u_{*}}{k} \ln \frac{z-d}{z_{0}} & z_{0}+d<z<\frac{\zeta_{u}|L|}{k}+d, \\ \frac{u_{*}}{k}\left[a_{u}+C_{u}\left(\frac{k(z-d)}{L}\right)^{-\frac{1}{3}}+\ln \frac{-L}{k z_{0}}\right] & \frac{\zeta_{u}|L|}{k}+d \leq z \leq h,\end{cases}
$$

where $\zeta_{u} \approx 0.1, a_{u} \approx 0.7$ and $C_{u} \approx 1.4$ are dimensionless constants (see [11]). The angle of wind turn in the boundary layer is given by the expression:

$$
\sin \alpha=\sin \left(\alpha_{s}-\alpha_{h-0}\right)=\frac{a_{\alpha}}{k}\left(\frac{h k}{|L|}\right)^{-\frac{1}{3}} \frac{u_{*}}{|\bar{u}|} \operatorname{sign} f,
$$

where $\alpha_{s}$ and $\alpha_{h-0}$ are the angles between the wind direction and $x$-axis at the terrain and $z=h$, respectively. The estimation of $a_{\alpha}=3$ was proposed in [23]. The mean wind velocity $|\bar{u}|$ in the CBL is obtained from:

$$
|\bar{u}|=|u|_{h-0}=\frac{u_{*}}{k}\left[a_{u}+\ln \frac{-L}{k z_{0}}\right],
$$

if we consider $h \gg|L|$. In practice, we assume that the wind turn angle varies linearly with height and reaches zero at the top of the CBL Finally, note that in the CBL wind profile, the calculation of the surface friction velocity $u_{*}$ from the horizontal wind velocity interpolated at $z=z_{m}, u_{0}\left(z_{m}\right)$, is generally straightforward using (14a):

$$
u_{*}=\frac{k\left|u_{0}\left(z_{m}\right)\right|}{\ln \frac{z_{m}-d}{z_{0}}} .
$$

In the case that $z_{m} \geq \frac{\zeta_{u}|L|}{k}+d$, we have to use (14b).

Some limitations of this wind profile should be mentioned. First, an important issue in wind modelling is that near-surface wind speeds in the zone near the crests of topographic features such as ridges and hills show mark increases when compared to the equivalent wind speeds measured at the same height above flat terrain. This aspect is more significant when the initial wind profile is constructed from a set of measures of distributed stations in a region with pronounced topographic features, where there is a chance of a hill not containing wind speed information. This issue is less usual in downscaling procedures 
where the wind field information arises from the regular grid of a NWP model. This effect is related to the following aspects of our model. On the one hand, the accuracy of the wind speed results near the terrain is related with the quality of the surface discretisation. This aspect is handled by using adaptive meshes of tetrahedra that are refined around drastic geographical features. On the other hand, the terrain surface boundary condition applied in the mass-consistent model (no flow through boundary condition) forces the wind to be tangent to the terrain and, since the mass is preserved, it generates an speed up in the ridges and hills. Other aspects related to the wind speed up as, for example, isolated surfaces are not considered in this model.

Second, this model does not consider the inner boundary layers caused by a terrain with different roughness. This phenomenon is somehow approached by the application of the mass-consistent model to the initial wind profile that we construct in terms of $z_{0}$ and $d$. Since, the optimisation of $z_{0}$ and $d$ is subject to some measured or predicted values, an initial, but partial, solution of this problem could be to use some data given at a suitable height. Unfortunately, in practice there is not sufficient (measured or predicted) wind information at each land cover type location and, therefore, this strategy is not always possible.

\section{Parameter estimation}

The results of the mass-consistent modelling have proved to be very sensitive to the values of $\alpha, \xi, z_{0}$, and $d$. Thus, an accurate definition of these parameters is critical to obtain a reliable wind field. We have to estimate a value of $\alpha$ and $\xi$ for the whole domain [6], and a value of $z_{0}$ and $d$ for each land cover class. This means that the number of unknowns depends on the number of different land covers in the region of interest. These parameters are estimated using a memetic method to optimise a fitness function that we describe in this section.

\subsection{Fitness function}

The objective of the optimisation is to find the values of the parameters such that the wind computed with the model is the most similar to a known wind at some control points. The wind values at the control points can be known from the HARMONIE-AROME model or measurement stations. To measure 
the error between the model and the known data, we will use the RMSE, i.e.,

$$
R M S E=\sqrt{\frac{1}{n_{c}} \sum_{i=1}^{n_{c}}\left(u_{x i}-u_{x i}^{c}\right)^{2}+\left(u_{y i}-u_{y i}^{c}\right)^{2}+\left(u_{z i}-u_{z i}^{c}\right)^{2}},
$$

where $n_{c}$ is the number of control points, $\left(u_{x i}, u_{y i}, u_{z i}\right)$ and $\left(u_{x i}^{c}, u_{y i}^{c}, u_{z i}^{c}\right)$ are, respectively, the wind velocity obtained with the mass-consistent model and the known wind at the $i^{\text {th }}$ control point. So, the parameter estimation consists of the minimisation of the RMSE. Note that for each evaluation of the fitness function, the wind model has to be executed.

\subsection{Optimisation algorithm}

The optimisation strategy is based on a memetic method composed of three tools: DE [89], a Rebirth Operator (RBO) [90], and the L-BFGS-B algorithm [91]. DE is an evolutionary algorithm that utilises a population composed of a fixed number $n_{v}$ of $D$-dimensional parameter vectors $p_{i, g}$ for each generation $g$; $g=1, \ldots, n_{g}$. The initial population, which must cover the parameter searching space, is chosen randomly. The mutation procedure modifies an existing vector by adding to itself a weighted difference between two other vectors. In the crossover step, these mutated vectors are mixed with another target vector to obtain the so-called trial vector. If the trial vector yields a lower fitness function value than the target vector, the target vector is replaced by the trial vector (selection). Each population vector has to serve as target vector at least once, so $n_{v}$ competitions will take place per generation.

The accuracy of the results obtained using DE may be insufficient. To increase it, we have run $n_{e} \mathrm{DE}$ experiments and have performed a statistic analysis of the results obtained for each one. This analysis will allow us to reduce the search interval. Let $p_{i, n_{g}}^{j}\left(j=1, \ldots, n_{e} ; i=1, \ldots, n_{u}\right)$ be the estimation of the $n_{u}$ unknown parameters obtained in each of the $n_{e}$ experiments. We can compute its average $\bar{p}_{i, n_{g}}$, and standard deviation $\sigma_{i, n_{g}}$. Then, the search interval can be reduced to the confidence interval of each variable, i.e., $\bar{p}_{i, n_{g}} \pm \frac{\sigma_{i, n_{g}}}{\sqrt{n_{e}}} T_{n_{e}-1, \frac{\tau}{2}}$, where $1-\tau$ is the confidence coefficient and $T$, the Student's t-distribution. If one extreme of the new interval exceeds the old extreme, the latter is preserved. This allows the rebirth of a new population to restart 
DE. This procedure may be repeated as many times as required. Note that the $n_{e} \mathrm{DE}$ experiments can be run in parallel.

When the last generation of the last reborn population is evaluated, the best parameter vector among all the DE experiments is selected to be the starting point of the L-BFGS-B algorithm. This algorithm is a procedure for solving large non-linear optimisation problems with simple bounds. It is based on the gradient projection method and uses a limited memory BFGS matrix to approximate the Hessian of the fitness function. The results of this final minimisation will be the estimated parameters.

\section{Results}

In this section, two experiments are presented. The first one validated the methodology in a simple test involving a near flat terrain. The values of the parameters were known in advance, and we used our methodology to recover them. The second experiment was an application in an eastern location of Gran Canaria Island, using the HARMONIE-AROME and ECMWF models and the measurement wind data from the AEMET network of stations.

\subsection{Test numerical experiment}

The domain of this experiment is a $2 \mathrm{~km} \times 1.5 \mathrm{~km}$ rectangular region composed of a grid of $6 \times 5$ different land cover polygons; see Fig. 2. The height of the domain was $2 \mathrm{~km}$. The terrain surface contained three artificial hills of $50 \mathrm{~m}$ height (smooth terrain). A mesh of 8526 nodes and 42568 tetrahedra, adapted to the terrain, was generated using the meccano mesh generator [92, 93].

For a more realistic example, each of the thirty polygons of the test was defined as a compound coverage made up as a weighted average of some basic ones. Note that some cells had the same configuration, e.g., cells 2, 4 and 8, and 10,11, 15 and 17, respectively. This configuration increased the difficulty of the problem since the effect of some types of coverage was negligible in the RMSE.

To define the test input data for the mass-consistent model, first, we fix $\alpha=0.1$ and $\xi=0.5$ in the whole domain. The values of $z_{0}$ and $d$ are equal to the corresponding mean of the nominal values given in Table 1 (Eq. 1 for $z_{0}$ and 
Eq. 2 for $d$ ) for each polygon configuration. In addition, we considered a Truly Neutral atmosphere, i.e., $\mu_{n}=0$ and $B_{s}=0$. Next, we selected 10 points at $10 \mathrm{~m}$ above $z_{t}+d$, and imposed constant wind of $10 \mathrm{~m} \mathrm{~s}^{-1}$ and East direction. Once the input data were defined, we computed a three-dimensional wind field using our mass-consistent model. The results obtained at 5 different heights for 5 locations per polygon were used as control points in the optimisation problem $(5 \times 5 \times 30$ control points). The objective was to recover the prescribed values of $\alpha, \xi, z_{0}$, and $d$ using the memetic procedure described in Sect. 7. The initial search intervals were $\left[10^{-2}, 10\right]$ for $\alpha,[0,1]$ for $\xi$, and the ranges of variation given in Table 1 for $z_{0}$ and $d$. The number of parallel DE experiments $\left(n_{e}\right)$ was 8.

\begin{tabular}{|l|l|l|l|l|l|}
\hline 25 & 26 & 27 & 28 & 29 & 30 \\
3.04 & $6 \times 10^{-1}$ & $5 \times 10^{-2}$ & 8.18 & 4.68 & 1.52 \\
$2.11 \times 10^{-2}$ & $1.1 \times 10^{-1}$ & $1 \times 10^{-2}$ & $2.39 \times 10^{-1}$ & $1.16 \times 10^{-1}$ & $2.1 \times 10^{-3}$ \\
\hline 19 & 20 & 21 & 22 & 23 & 24 \\
6.93 & 2.27 & 2.15 & 8.4 & 2.17 & 4.82 \\
$2.73 \times 10^{-1}$ & $1.85 \times 10^{-2}$ & $1.26 \times 10^{-2}$ & $1.49 \times 10^{-1}$ & $5.56 \times 10^{-3}$ & $1.82 \times 10^{-1}$ \\
\hline 13 & 14 & 15 & 16 & 17 & 18 \\
5.07 & $3.12 \times 10^{1}$ & 6.81 & 3.04 & 6.81 & 3.35 \\
$1.8 \times 10^{-2}$ & $5.68 \times 10^{-3}$ & $2.08 \times 10^{-2}$ & $5.69 \times 10^{-2}$ & $2.08 \times 10^{-2}$ & $5.92 \times 10^{-2}$ \\
\hline 7 & 8 & 9 & 10 & 11 & 12 \\
7.38 & 5.1 & 8.34 & 6.81 & 6.81 & 3.72 \\
$2.33 \times 10^{-1}$ & $2.25 \times 10^{-1}$ & $3.33 \times 10^{-1}$ & $2.08 \times 10^{-2}$ & $2.08 \times 10^{-2}$ & $1.3 \times 10^{-2}$ \\
\hline 1 & 2 & 3 & 4 & 5 & 6 \\
$2.55 \times 10^{1}$ & 5.1 & 6.09 & 5.1 & 6.93 & 8.3 \\
$7.85 \times 10^{-4}$ & $2.25 \times 10^{-1}$ & $1.99 \times 10^{-1}$ & $2.25 \times 10^{-1}$ & $2.73 \times 10^{-1}$ & $3.41 \times 10^{-1}$ \\
\hline
\end{tabular}

Figure 2: Test region with the 30 polygons related to SIOSE compound coverages. In each cell, from top, we have the cell number related to results in Table $2, d(\mathrm{~m})$ and $z_{0}(\mathrm{~m})$, respectively.

Table 2 summarises the results of this experiment. Columns 2 and 3 list the values of the relative errors in percentage between the estimated $z_{0}$ and $d$ and the corresponding target values for each polygon, respectively, after 8 DE processes were run. This first stage of the optimisation process yielded an $R M S E$ of $3.57 \times 10^{-3}$ and the relative errors of $\alpha$ and $\xi$ were $0.07 \%$ and $8.77 \%$, respectively. The results seem to be accurate, except for the cells 20 , 26 and 27 , where $d$ estimations were quite far from the target values. Next, we reduced the search intervals by applying Student's t-distribution to the $8 \mathrm{DE}$ results. Then, eight more DE processes were run with the new intervals, and the best result was improved using L-BFGS-B, obtaining $R M S E=8.15 \times 10^{-4}$, 
Table 2: Results of the test experiment. Relative errors were computed against target values.

\begin{tabular}{|c|c|c|c|c|}
\hline Cell & $\begin{array}{l}\text { DE }\left(z_{0}\right) \\
\text { Relative } \\
\text { error (\%) }\end{array}$ & $\begin{array}{l}\text { Rebirth DE + } \\
\text { L-BFGS-B }\left(\mathbf{z}_{0}\right) \\
\text { Rel. error (\%) }\end{array}$ & $\begin{array}{l}\text { DE }(d) \\
\text { Relative } \\
\text { error (\%) }\end{array}$ & $\begin{array}{l}\text { Rebirth DE }+ \\
\text { L-BFGS-B (d) } \\
\text { Rel. error (\%) }\end{array}$ \\
\hline 1 & 5,87 & 0,51 & 0,42 & 0,06 \\
\hline 2 & 1,64 & 0,07 & 0,48 & 0,08 \\
\hline 3 & 2,33 & 0,69 & 2,32 & 0,67 \\
\hline 4 & 1,64 & 0,07 & 0,48 & 0,08 \\
\hline 5 & 1,92 & 0,11 & 1,59 & 0,17 \\
\hline 6 & 0,85 & 0,68 & 0,01 & 0,44 \\
\hline 7 & 0,55 & 0,19 & 0,45 & 0,03 \\
\hline 8 & 1,64 & 0,07 & 0,48 & 0,08 \\
\hline 9 & 1,31 & 0,19 & 0,04 & 0,10 \\
\hline 10 & 0,96 & 0,19 & 0,63 & 0,10 \\
\hline 11 & 0,96 & 0,19 & 0,63 & 0,10 \\
\hline 12 & 4,35 & 0,35 & 6,92 & 1,05 \\
\hline 13 & 4,85 & 3,41 & 1,62 & 0,55 \\
\hline 14 & 0,96 & 0,77 & 0,42 & 0,06 \\
\hline 15 & 5,58 & 0,19 & 0,63 & 0,10 \\
\hline 16 & 0,96 & 0,84 & 6,74 & 1,02 \\
\hline 17 & 1,92 & 0,19 & 0,63 & 0,10 \\
\hline 18 & 10,83 & 2,95 & 2,48 & 4,17 \\
\hline 19 & 1,07 & 0,11 & 1,59 & 0,17 \\
\hline 20 & 0,23 & 2,37 & 23,70 & 2,87 \\
\hline 21 & 5,38 & 0,49 & 5,16 & 2,09 \\
\hline 22 & 6,53 & 0,13 & 0,04 & 0,08 \\
\hline 23 & 5,07 & 0,70 & 5,77 & 1,21 \\
\hline 24 & 7,45 & 0,11 & 8,06 & 0,20 \\
\hline 25 & 6,84 & 1,42 & 5,37 & 1,88 \\
\hline 26 & 6,88 & 0,56 & 41,04 & 6,39 \\
\hline 27 & 0,21 & 1,20 & 39,85 & 69,69 \\
\hline 28 & 0,61 & 0,68 & 0,32 & 0,43 \\
\hline 29 & 6,37 & 1,18 & 7,01 & 0,99 \\
\hline 30 & 9,26 & 0,77 & 7,02 & 0,98 \\
\hline
\end{tabular}


$\alpha=0.1$ and $\xi=6,81 \times 10^{-1}$ (relative errors of $0.01 \%$ and $36.2 \%$, respectively). The new relative errors of $z_{0}$ and $d$ at this stage are shown in columns 4 and 5 , in this order. The rebirth procedure improved the estimations of most of the roughness parameters. However, there were a few cases where the relative error was increased. In particular, the case of $d$ in cell 27 that reached an error of $69.69 \%$. This was because the target value of $d$ in that cell is very small $\left(5.00 \times 10^{-2} \mathrm{~m}\right)$ in comparison with other cells and, therefore, the model is not sensitive to this value. This is also the case of $\xi$. In equation (8), any value of $\xi$ would have produced the same result since all the measures have the same value and the same height over $z_{t}+d$. Thus, any of them would be a correct estimation.

Regarding the computational cost of this experiment, the average runtime of the DE procedures was about $4 \mathrm{~h} 47 \mathrm{~min}$ for 300 iterations, with a population size of 342, involving 57 unknown parameters; this led to 102, 942 evaluations of the fitness function $(0.167 \mathrm{~s} /$ evaluation). The rebirth procedure, including the L-BFGS-B algorithm, run during 5 h 39 min with the same DE strategy but 117, 964 fitness function evaluations. All the processes were run in parallel on a cluster of 24 nodes. Each node is composed of 2 Intel Xeon E5645 Westmere-EP processors, each of them with 6 cores. Therefore, in general, the results of this experiment indicate, for this case, the effectiveness of our methodology and the convenience of applying the rebirth strategy.

\subsection{Application to Gran Canaria Island}

In this experiment, we apply the described methodology to a region of the Gran Canaria island. The downscaling model uses the forecast from HARMONIEAROME and ECMWF. The memetic algorithm estimates the roughness length and displacement height.

The region of interest is a rectangular domain of $12 \mathrm{~km} \times 28.5 \mathrm{~km} \times 3 \mathrm{~km}$ located at the East of Gran Canaria Island. The tetrahedral mesh is adapted to the terrain with additional local refinement around the measurement stations and the shoreline; see a detail of the terrain triangulation in Fig. 3. The mesh contains 44970 tetrahedra and 10070 nodes.

The land coverages are taken from the SIOSE database. Since, in Gran Canaria, the range of variation of environmental temperature is rather small 
throughout the year, the land coverages may be considered constant in size and shape. Precisely, in the region of interest, there are 1216 land cover polygons, each with a particular combination of 26 basic coverages.

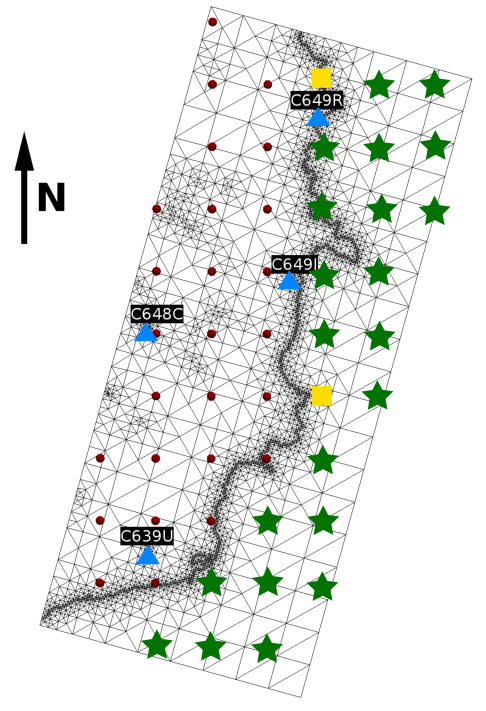

Figure 3: Detail of the terrain of the adaptive mesh of Gran Canaria Island. The symbols indicate the locations of the data falling inside the domain: the triangles represent the measurement stations; the stars, the control points of HARMONIE-AROME only; the squares, the control points of both HARMONIE-AROME and ECMWF; and the circles, the additional grid points of HARMONIE-AROME used in the mass-consistent model.

The roughness parameters depend on wind velocity and stability due to the fact that they characterise the surface that influences the wind speed profile (socalled footprint). This footprint is dependent on stability and height (in general, boundary layer conditions), and so indirectly are the roughness parameters. The stability dependence of the roughness length and displacement height was demonstrated by [94]. For this reason, we have chosen six episodes to carry out the experiment, each one corresponding to a different stability class. Table 3 shows the selected episodes indicating the stability class, the $10 \mathrm{~m}$ wind speed and direction, and the values of the $B_{s}, N_{2 h-h}, W_{*}$, and $V_{*}$. These values are the HARMONIE-AROME predictions for June 2015. The stability class has been defined using the $B_{s}$ values and $N_{2 h-h}$ or the comparison between $W_{*}$ and $V_{*}$ values, according to Zilitinkevich et al. [25]. We want to emphasise that, 
Table 3: Selected wind episodes in an Eastern region of Gran Canaria Island during June 2015.

\begin{tabular}{|c|c|c|c|c|c|}
\hline $\begin{array}{l}\text { BL } \\
\text { stability }\end{array}$ & $\begin{array}{r}\text { HARMONIE } \\
10 \mathrm{~m} \text { wind } \\
\text { speed }\left(\mathrm{ms}^{-1}\right)\end{array}$ & $\begin{array}{l}\text { HARMONIE } \\
10 \mathrm{~m} \text { wind } \\
\text { direction }\left(^{\circ}\right)\end{array}$ & $\begin{array}{r}\text { Surf. buoy. } \\
\text { flux, } \mathrm{B}_{\mathrm{s}} \\
\left(\mathrm{m}^{2} \mathrm{~s}^{-3}\right)\end{array}$ & $\begin{array}{r}\text { B-V freq. } \\
\mathrm{N}_{2 \mathrm{~h}-\mathrm{h}} \\
\left(\mathrm{s}^{-1}\right)\end{array}$ & $\begin{array}{r}\text { Ratio } \\
\mathbf{V}_{*} / \mathbf{W}_{*}\end{array}$ \\
\hline LS & 10.18 & $336.92-\mathrm{NNW}$ & $-1.38 \times 10^{-4}$ & $1.68 \times 10^{-2}$ & - \\
\hline NS & 6.10 & $331.46-\mathrm{NNW}$ & $-9.78 \times 10^{-4}$ & $\approx 0$ & - \\
\hline $\mathrm{TN}$ & 7.51 & $331.82-\mathrm{NNW}$ & $\approx 0$ & $\approx 0$ & - \\
\hline $\mathrm{CN}$ & 8.52 & $340.72-\mathrm{NNW}$ & $3.68 \times 10^{-3}$ & $1.04 \times 10^{-2}$ & - \\
\hline $\mathrm{PC}$ & 1.59 & $116.78-\mathrm{ESE}$ & $6.22 \times 10^{-3}$ & $1.54 \times 10^{-2}$ & 0.17 \\
\hline $\mathrm{MC}$ & 6.87 & $358.98-\mathrm{N}$ & $3.02 \times 10^{-3}$ & $1.74 \times 10^{-2}$ & 0.76 \\
\hline
\end{tabular}

although we have defined the third episode of Table 3 as Truly Neutral (the only case out of 240 for the whole period), it corresponds to a Conditionally Neutral boundary layer with very small $B_{s}$ and $N_{2 h-h}$. The same occurs with the Nocturnal Stable case, which may also be considered as a Long-Lived Stable boundary layer with a very small $N_{2 h-h}$. Moreover, the selected PC episode is the only one with ESE wind direction in that month. In the studied period, most episodes were LS (44.58\%), MC (41.25\%), or CN (9.58\%).

For each of the six chosen episodes, the memetic algorithm estimates the values of $\alpha$, and the 26 basic coverages $z_{0}$ and $d$. The searching space for the aerodynamic parameters is the one given in Table 1 . Regarding $\alpha$, its values ranges from $10 \times 10^{-2}$ to 1 in SBL and from 1 to 5 in CBL.

Table 4: Location in UTM zone $28 \mathrm{~N}$ coordinates and heights above the sea level of the anemometers used in the numerical application in Gran Canaria Island.

\begin{tabular}{llrrr}
\hline Code & Name & $\boldsymbol{x}(\mathrm{m})$ & $\boldsymbol{y}(\mathrm{m})$ & $\boldsymbol{z}(\mathrm{m})$ \\
\hline C639U & San Bartolomé de Tirajana, El Matorral & 455345 & 3076503 & 51 \\
C648C & Aguimes & 455326 & 3086484 & 316 \\
C649I & Gran Canaria, Aeropuerto & 461659 & 3088640 & 34 \\
C649R & Telde, Melenara & 462855 & 3095805 & 19 \\
\hline
\end{tabular}

Wind measures at four stations of the AEMET network are available in the studied region. Their UTM coordinates and heights above sea level are given 
in Table 4 and shown in Fig. 3. It should be noted that data from more wind stations should have been desirable to achieve a more definite validation.

Two different experiments have been carried out; one using data from HARMONIE-AROME, and the other using data from ECMWF. Figure 3 shows the grid points from both NWP models. The wind velocities are plotted for a particular episode. The interpolated wind field is constructed from the NWP wind velocities at $10 \mathrm{~m}$.

Finally, we estimate the parameters using the memetic algorithm described in Sect. 7. The control points used to compute the RMSE are different for the two experiments. In the case of the HARMONIE-AROME, there are 28 control points: the four stations wind data and the 24 HARMONIE-AROME $10 \mathrm{~m}$ wind located over the sea. In the ECMWF experiment, there are the four stations and two more ECMWF points over the sea (see Fig. 3).

Table 5: Results of the experiments in Gran Canaria Island using data from HARMONIE$\operatorname{AROME}\left(z_{0}\right.$ and $d$ in meters).

\begin{tabular}{lllllll}
\hline Wind direction & NNW & NNW & NNW & NNW & N & N \\
Wind speed $\left(\mathbf{m s}^{-1}\right)$ & $\boldsymbol{v}>\mathbf{6}$ & $\boldsymbol{v}>\mathbf{6}$ & $\boldsymbol{v}>\mathbf{6}$ & $\boldsymbol{v}>\mathbf{6}$ & $\boldsymbol{v} \leq \mathbf{2}$ & $\boldsymbol{v}>\mathbf{6}$ \\
Stability & LS & NS & TN & CN & PC & MC \\
\hline RMSE(H-A) & 8.47 & 3.12 & 5.94 & 7.89 & 3.29 & 2.46 \\
RMSE(H-A/W3D) nominal values & 4.00 & 3.47 & 4.74 & 6.21 & 2.55 & 2.40 \\
RMSE(H-A/W3D) estimated values & 2.44 & 2.59 & 3.47 & 4.78 & 2.27 & 1.31 \\
RMSE(ECMWF) & 7.08 & 3.88 & 3.16 & 6.14 & 2.97 & 2.98 \\
RMSE(ECMWF/W3D) nominal values & 4.00 & 3.47 & 4.74 & 6.21 & 2.55 & 5.90 \\
RMSE(ECMWF/W3D) estimated values & 2.56 & 2.91 & 3.68 & 4.79 & 2.53 & 2.35 \\
\hline
\end{tabular}

The results of the experiments are condensed in Table 5 as the RMSE values for the six episodes. These RMSE values are always constructed against the measurement wind data from the meteorological stations.

The first three rows correspond to the HARMONIE-AROME experiment, while the last three correspond to the ECMWF experiment. Each group of three rows has to be read the same way: the first row is the RMSE obtained by NWP forecast; the second row is the error obtained by the downscaling model Wind3D using the nominal values from Table 1; i.e. without using the memetic algorithm; and the third row are the errors obtained by the complete procedure 


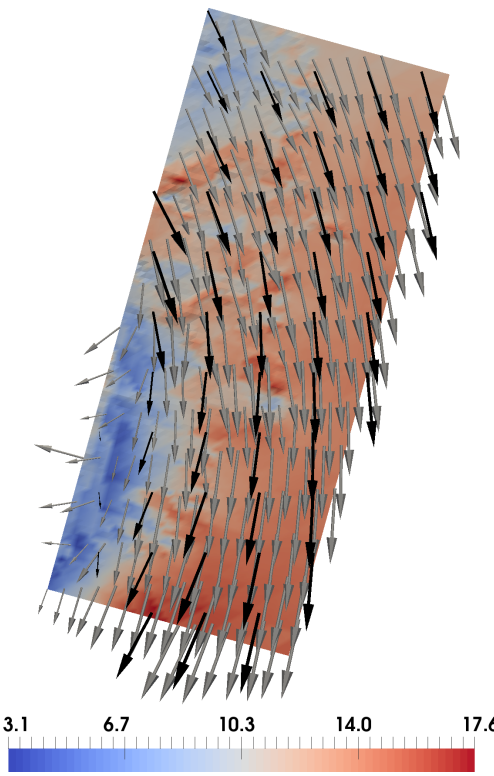

(a) Long-Lived Stable
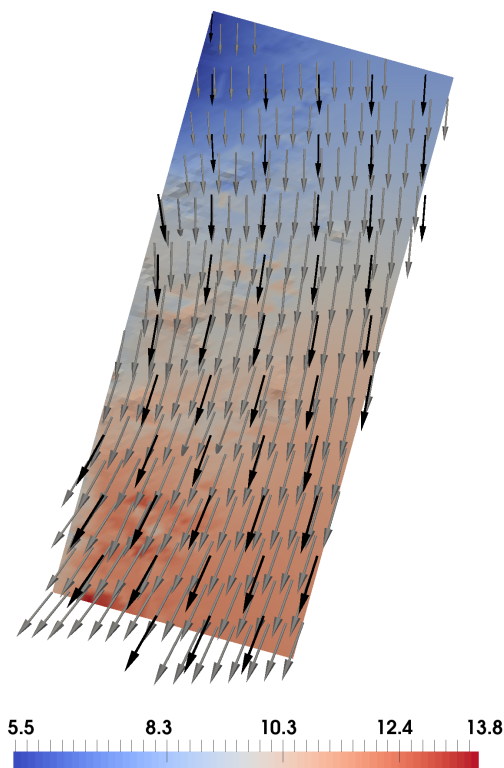

(b) Mechanically-Convective Layer

Figure 4: Detail of $10 \mathrm{~m}$ wind velocities in the (a) LS and (b) MC cases of Table 3. The colours represent the wind speed obtained by Wind3D. The black vectors are the wind velocities provided by HARMONIE-AROME. The grey vectors are the downscaled wind velocities.

described in this paper.

Looking at the results, in the HARMONIE-AROME experiment, there has been an improvement between $16.99 \%$ and $71.19 \%$ comparing the results from the NWP and the wind obtained using the described procedure. In the ECMWF experiment, the improvement is similar to the one obtained in the HARMONIEAROME experiment, except in the TN episode. In this case, the downscaling model has not been able to improve the ECMWF forecasting. Looking at the differences in RMSE between the downscaling forecast using nominal or estimated values, the necessity of estimating $z_{0}$ and $d$ gets clear; the errors are always smaller for the estimated values.

Figure 4 represents the forecast $10 \mathrm{~m}$ wind velocities for the LS and MC episodes. The wind field represented is the HARMONIE-AROME forecast and the Wind3D with estimated values results. We observe that the mass-consistent model reproduced the HARMONIE-AROME wind, but providing a more accu- 
rate wind in the microscale and improving the predictions in the surroundings of the measurement stations, as seen in Table 5.

A note on computational time is relevant. The average runtime of each DE procedure is $6 \mathrm{~h}$ and $39 \mathrm{~min}$. The DE algorithm consists of 300 iterations, with a population size of 294, involving 49 unknown parameters, which leads to 88493 evaluations of the fitness function ( $0.271 \mathrm{~s}$ per evaluation). The rebirth procedure, including the L-BFGS-B algorithm, runtime is $5 \mathrm{~h} 28 \mathrm{~min}$ consisting of 232 iterations with 71810 fitness function evaluations. All the processes were run in the same cluster described in the test experiment.

\section{Discussion}

The selected experiments are located over non-complex terrain to overcome the limitations of the mass-consistent model and provide reliable and meaningful results of wind adjustment. The literature indicates that the values of the parameters change for different atmospheric states (wind speed, direction and stability). This dependence can be seen if we study the estimated values of $z_{0}$ and $d$ in the Gran Canaria experiment for the different episodes.

Studying the largest coverage, AMO (47.74\% of the domain), for the ECMWF experiment, the estimated values of $z_{0}^{A M O}$ are the maximum in the searching interval; in the HARMONIE-AROME experiment they tend to the maximum limit in the CBL cases. Since there are not any control points over the sea in the ECMWF experiments, we consider the results from HARMONIE-AROME more reliable. The largest land coverage in the domain is MTR (15.54\%). In this case, the estimated values of $z_{0}^{M T R}$ and $d^{M T R}$ vary from the minimum to the maximum values depending on the BL stability. In the SDN coverage (9.24\%), both NWP models reach similar results of the roughness parameters, except for the LS case. Also, for CHL coverage $(5.68 \%)$ both models agree about the values of $z_{0}^{C H L}$, reaching the maximum in SBL and the minimum in CBL. For both NWP models, the $d^{C H L}$ values are similar, except for the PC stability. Regarding the EDF coverage, the displacement height reaches the maximum value for any stability and NWP model. However, $z_{0}^{E D F}$ tends to the minimum value in LS, NS, TN and MC, while in $\mathrm{PC}$ reaches the maximum value, for both models. In $\mathrm{CN}$ the results differ about a $20 \%$ of the total range 
near the minimum. Each of the other coverages represents less than a $3 \%$ of the domain surface.

One valuable observation is that the estimated values of $z_{0}$ and $d$ are always different from the nominal values found in the literature. This can be explained, not only because they are fitting parameters, but also because the values of $z_{0}$ and $d$ are dependent on regional characteristics of the land coverages. The results found in the experiments indicate that the estimated values always yield a smaller error. For this reason, we think that it is critical to estimate the parameters. It is important to remember that the proposed method estimates the values of $z_{0}$ and $d$ that are better suited for the combination of basic coverages found in the land cover database; so the estimated values may not be an accurate value for the aerodynamic parameters as such.

Concerning the values of $\alpha$, it is normally lower in SBL (stable and neutral conditions) than in CBL (unstable conditions). In our experiments, $\alpha$ tends to the upper bound (1) in SBL cases, i.e., the model tried to adjust the wind velocities changing the vertical component and preserving the horizontal ones as much as possible. However, in CBL episodes a greater variation of the vertical component is allowed, and the values of $\alpha$ also tend to the upper bound (5) in all cases except for the MC stability in the ECMWF experiment where the value estimated is 4 . The parameter $\xi$ could affect the wind results if the input data of wind were given on a dispersed grid, but it is not the usual case in downscaling problems; therefore, $\xi$ does not apply.

Comparing the values of the estimated parameters for the HARMONIEAROME and the ECMWF experiments, there is general agreement between the values for each stability condition. However, while some parameters reach the same values, e.g., $z_{0}^{E D F}, d^{E D F}, \alpha$, others are estimated in the opposite bound of the interval, e.g., $z_{0}^{A C M}, z_{0}^{L F N}, d^{P D A}, d^{V A P}, d^{Z A U}$. Moreover, for both experiments, some parameters are estimated to the same values most days, there are others that differ greatly between days, e.g., $z_{0}^{A R R}, z_{0}^{L A A}, z_{0}^{P S T}, z_{0}^{S D N}, z_{0}^{S N E}$, $z_{0}^{Z A U}, z_{0}^{Z E V}, d^{M T R}, d^{L F C}$. These divergences show that the proposed methodology is strongly dependent on the forecast values of the mesoscale model, which determine the quality of the predicted wind field. For this reason, we suggest running the methodology for each NWP independently. 
An important aspect to be considered is a sensitivity analysis of the involved parameters. Some coverages may show little effect on the resulting wind field. As a result, a reduction of the number of unknowns may be possible by not considering those parameters. Another aspect that can be considered is the fact that a basic coverage may affect different regions with very diverse characteristics. In the current implementation, each parameter is represented by a single value, even when their optimal values could be different in each region. The more a basic cover appears in different locations, the more a unique estimation is not optimal for each of them separately. For this reason, if the sensitivity analysis determines that the results of the model are highly dependent on those parameters, it may be worth to consider different unknowns for each region.

Finally, this methodology can be applied to construct a reduced basis for its use in wind forecasting. To this end, a larger period should be studied (at least one year). This would allow to analyse all the wind condition types (speed, direction, atmosphere stability) occurring in Gran Canaria Island. Reduced Basis (RB) methods consist of seeking, for any new parameter value, in a subspace of lower dimension than the discretised PDE problem (high-fidelity problem), an approximate solution of that Hi-Fi problem, expressed as a linear combination of suitable basis functions that are dependent on the problem. To generate these basis functions, the set of solutions to the finite element problem (snapshots) are used; a suitably chosen set of parameter values may be, e.g., a selection of representative wind conditions. The procedure has two stages. On the one hand, the offline block including the high-fidelity discretisation, the generation of solution snapshots by Proper Orthogonal Decomposition (POD) and the construction of the projection matrices. On the other hand, for a chosen parameter value, we have to assemble and solve the $\mathrm{RB}$ system to obtain the projected solution and, then, recover the solution in the original dimension. A detailed description of RB can be found in $[95,96]$.

\section{Conclusions}

This paper presents a methodology to improve the downscaling forecasting by estimating the parameters involved. These parameters are the ratio of the Gauss precision moduli $\alpha$, that appears in the elliptic problem of the PDE 
(eq. 7a, 7b, 7c); the weighting parameter $\xi$ of the horizontal interpolation of wind velocities (eq. 8); and the roughness length $z_{0}$ and the displacement height $d$ of each basic cover class in the logarithmic wind profile (eq. 12a, 12b, 14a, 14b). To estimate these parameters, a memetic algorithm, consisting of the DE method and L-BFGS-B algorithm, combined with a rebirth procedure based on Student t-distribution confidence interval, is proposed.

This procedure has been applied to two different experiments. The first is a synthetic test with known target values of the parameters, where the method was able to estimate the values of most of them with a small error. Just one estimation of $d$ for a compound coverage was not successfully obtained because the model was not sensitive to such a small value of $d$. Nevertheless, the effect of this error in the downscaling wind was negligible. In the second experiment, a real case in Gran Canaria Island was carried out. In this case, the input values of the model came from two different models: HARMONIE-AROME, and ECMWF; and the control points were some measurement stations and the mesoscale model nodes over the sea. Different episodes with different atmospheric conditions have been considered. In all cases, the wind prediction of the mass-consistent model with the estimated parameters was closer to the measurement data than the one provided by the mesoscale model.

Accordingly, we conclude that the proposed approach - combining parameter estimation and a mass-consistent model - is an efficient tool for NWP downscaling. Nevertheless, since this diagnostic model has limitations, in future research, we will implement the momentum conservation law into our wind model to improve the accuracy of diagnostic wind modelling in complex terrain. Another issue to be studied is the hypothesis, admitted in this work, that the mass-consistent model, with mass continuity law and no flow through boundary condition on the terrain surface, faithfully reproduces the near-surface speed up caused by topographic features. This should be checked and compared with any correction procedure like MS-Micro; see, e.g., [13, 97]. Finally, further research should be carried out to add the footprint effect to the wind profile formulation of Wind3D model to consider inner boundary layers in the starting wind.

We remark that the parameter estimations obtained for different wind and atmospheric conditions show that the mass-consistent model results are sensitive 
to the aerodynamic parameters for most coverages. In fact, small variations in the wind speed or direction may lead to considerably different parameter values, in agreement with the literature. For this reason, we propose to use this method combined with reduced basis. The reduced basis is grounded on the resulting parameters for a set of representative atmospheric conditions. Using the reduced basis, the microscale wind field could be computed using the mass-consistent model in a cost-efficient manner. However, further discussion about a suitable construction of such reduced basis from the results obtained in this work should be carried out.

\section{Acknowledgements}

This work has been supported by the Spanish Government, "Secretaría de Estado de Investigación, Desarrollo e Innovación", "Ministerio de Economía y Competitividad", and FEDER, grant contract: CTM2014-55014-C3-1-R The authors are also grateful to Dr David Greiner for his technical support and Dr M. Victoria Domínguez for her editorial assistance.

\section{References}

[1] Mahrt, L., Vickers, D., Edson, J., Wilczak, J.M., Hare, J., Højstrup, J.. Vertical structure of turbulence in offshore flow during Rasex. Bound-Lay Meteorol 2001;100(1):47-61.

[2] Emeis, S., Knoche, H.. Chapter 26 applications in meteorology. In: Developments in Soil Science. Elsevier; 2009, p. 603-622. doi:10.1016/ s0166-2481 (08) 00026-3.

[3] Jancewicz, K., Szymanowski, M.. The relevance of surface roughness data qualities in diagnostic modeling of wind velocity in complex terrain: A case study from the śnieżnik massif (SW poland). Pure and Applied Geophysics 2016;174(2):569-594. doi:10.1007/s00024-016-1297-9.

[4] Rodríguez, E., Montero, G., Escobar, J.M., Montenegro, R., Oliver, A.. Wind3D. http://www.dca.iusiani.ulpgc.es/Wind3D; 2012. 
[5] Montero, G., Montenegro, R., Escobar, J.M.. A 3-D diagnostic model for wind field adjustment. J Wind Eng Ind Aerod 1998;74-76:249-261. doi:10.1016/S0167-6105(98)00022-1.

[6] Montero, G., Rodríguez, E., Montenegro, R., Escobar, J.M., GonzálezYuste, J.M.. Genetic algorithms for an improved parameter estimation with local refinement of tetrahedral meshes in a wind model. Adv Eng Softw 2005;36(1):3-10. doi:10.1016/j . advengsoft.2004.03.011.

[7] Oliver, A., Rodríguez, E., Escobar, J.M., G., , Hortal, M., Calvo, J., et al. Wind forecasting based on the HARMONIE model and adaptive finite elements. Pure Appl Geophys 2015;172(1):109-120. doi:10.1007/ s00024-014-0913-9.

[8] Andersson, E.. User guide to ECMWF forecast products. Tech. Rep.; ECMWF; 2015.

[9] Bengtsson, L., Andrae, U., Aspelien, T., Batrak, Y., Calvo, J., de Rooy, W., et al. The HARMONIE-AROME model configuration in the ALADIN-HIRLAM NWP system. Monthly Weather Review 2017;doi:10 . 1175/MWR-D-16-0417.1; online.

[10] Sherman, C.A.. A mass-consistent wind model for wind fields over complex terrain. J Appl Meteorol 1978;17(3):312-319.

[11] Burlando, M., Georgieva, E., Ratto, C.F.. Parameterisation of the planetary boundary layer for diagnostic wind models. Bound-Lay Meteorol 2007;125:389-397. doi:10.1007/s10546-007-9220-7.

[12] Wagenbrenner, N.S., Forthofer, J.M., Lamb, B.K., Shannon, K.S., Butler, B.W.. Downscaling surface wind predictions from numerical weather prediction models in complex terrain with WindNinja. Atmos Chem Phys 2016;16(8):5229-5241. doi:10.5194/acp-16-5229-2016.

[13] Walmsley, J.L., Taylor, P.A., Keith, T.. A simple model of neutrally stratified boundary layer flow over complex terrain with surface roughness modulations (MS3DJH/3R). Bound-Lay Meteorol 1986;36(1-2):157-186. doi:10.1007/BF00117466. 
[14] Mortensen, N.G., Landberg, L., Troen, I., Petersen, E.L.. Wind atlas analysis and application program (WAsP). Vol. 2: User's guide. Roskilde, Denmark: Riso National Laboratory; 1993.

[15] Walmsley, J.L., Troen, I.B., Demetrius, P., Lalas, D.P., Mason, P.J.. Surface-layer flow in complex terrain: comparison of models and full-scale observations. Bound-Lay Meteorol 1990;52(3):259-281. doi:10.1007/BF00122090.

[16] Barnard, J.C.. An evaluation of three models designed for siting wind turbines in areas of complex terrain. Sol Energy 1991;46(3):283-294. doi:10.1016/0038-092X (91) 90096-F.

[17] Homicz, G.F.. Three-dimensional wind field modeling: a review. SAND Report 2597. Tech. Rep.; Sandia National Laboratories; Albuquerque, NM; 2002.

[18] Apsley, D.D., Castro, I.P.. Flow and dispersion over hills: comparison between numerical predictions and experimental data. J Wind Eng Ind Aerod 1997;67-68:375-386. doi:10.1016/S0167-6105(97)00087-1.

[19] Maurizi, A., Palma, J.M.L.M., Castro, F.A.. Numerical simulation of the atmospheric flow in a mountainous region of the north of Portugal. J Wind Eng Ind Aerod 1998;74-76:219-228. doi:10.1016/S0167-6105(98) 00019-1.

[20] Uchida, T., Ohya, Y.. Numerical simulation of atmospheric flow over complex terrain. J Wind Eng Ind Aerod 1999;81(1-3):283-293. doi:10. 1016/S0167-6105(99)00024-0.

[21] Lopes, A.M.G.. Windstation - a software for the simulation of atmospheric flows over complex topography. Environ Model Softl 2003;18(1):81-96. doi:10.1016/S1364-8152(02)00024-5.

[22] Montavon, C.. Validation of a non-hydrostatic numerical model to simulate stratified wind fields over complex topography. J Wind Eng Ind Aerod 1998;74-76:273-282. 
[23] Zilitinkevich, S.S., Fedorovich, E.E., Shabalova, M.V.. Numerical model of a non-steady atmospheric planetary boundary layer, based on similarity theory. Bound-Lay Meteorol 1992;59:387-411.

[24] Zilitinkevich, S.S., Johansson, P.E., Mironov, D.V., Baklanov, A.. A similarity-theory model for wind profile and resistance law in stably stratified planetary boundary layers. J Wind Eng Ind Aerod 1998;74-76:209-218.

[25] Zilitinkevich, S.S., Tyuryakov, S.A., Troitskaya, Y.I., Mareev, E.A.. Theoretical models of the height of the atmospheric boundary layer and turbulent entrainment at its upper boundary. Atmospheric and Oceanic Physics 2012;48(1):150-160. doi:10.1134/S0001433812010148.

[26] Abtew, W., Gregory, J.M., Borrelli, J.. Wind profile: Estimation of displacement height and aerodynamic roughness. Transactions of the ASAE 1989;32(2):0521-0527. doi:10.13031/2013.31034.

[27] National Technique Team SIOSE, . Documento Técnico SIOSE2005 - Versión 2.2. Tech. Rep.; D.G. Instituto Geográfico Nacional; Madrid; 2011. In Spanish.

[28] Brutsaert, W.. Evaporation into the atmosphere. D. Reidel Publish Company, Dordrecht, Holland; 1982.

[29] Kondo, J., Yamazawa, H.. Aerodynamic roughness over an inhomogeneous ground surface. Bound-Lay Meteorol 1986;35(4):331-348. doi:10.1007/ bf 00118563 .

[30] Bosveld, F.C.. Derivation of fluxes from profiles over a moderately homogeneous forest. Bound-Lay Meteorol 1997;84(2):289-327. doi:10.1023/a: 1000453629876 .

[31] Bossard, M., Feranec, J., Otahel, J.. CORINE land cover technical guide Addendum 2000. Tech. Rep.; European Environment Agency; Copenhagen; 2000 .

[32] National Technique Team SIOSE, . Manual de Fotointerpretación SIOSE Versión 2. Tech. Rep.; D.G. Instituto Geográfico Nacional; Madrid; 2011. In Spanish. 
[33] Makin, V.K.. A note on the drag of the sea surface at hurricane winds. Boundary-Layer Meteorology 2005;115(1):169-176. doi:10.1007/ s10546-004-3647-x.

[34] Roballo, S.T., Fisch, G.. Escoamento atmosfétrico no Centro de Lançamento de Alcântara (CLA): Parte I - Aspectos observacionais. Rev Bras Meteorol 2008;23(4):510-519. doi:10.1590/S0102-77862008000400010; in Portuguese.

[35] Fry, J.A., Xian, G., Jin, S., Dewitz, J.A., Homer, C.G., Yang, L., et al. Completion of the 2006 National Land Cover Database for the Conterminous United States. Photogramm Eng Rem S 2011;77(9):858-864.

[36] Molero-Paredes, T., Matos, A.. Efectos de la inducción artificial de la poliploidia en plantas de aloe vera(1.). Boletín del Centro de Investigaciones Biológicas 2008;42(1):111-133. In Spanish.

[37] Belward, A.S., Estes, J.E., Kline, K.D.. The IGBP-DIS global 1-km land-cover data set DISCover: A project overview. Photogramm Eng Rem S 1999;65(9):1013-1020.

[38] Troen, I., Petersen, E.L.. European Wind Atlas, 300 pp. Tech. Rep.; Ris $\varnothing$ National Laboratory; Roskilde, Denmark; 1989.

[39] Rotach, M.W.. Determination of the zero plane displacement in an urban environment. Bound-Lay Meteorol 1994;67(1-2):187-193. doi:10.1007/ BF00705513.

[40] Chang, Y., Tan, J., Grimmond, S., Tang, Y.. Distribution of Aerodynamic Roughness Based on Land Cover and DEM-A Case Study in Shanghai, China. In: ICUC9 - 9th International Conference on Urban Climate jointly with 12th Symposium on the Urban Environment. 2015,.

[41] Blocken, B., van der Hout, A., Dekker, J., Weiler, O.. CFD simulation of wind flow over natural complex terrain: Case study with validation by field measurements for Ria de Ferrol, Galicia, Spain. J Wind Eng Ind Aerod $2015 ; 147: 43-57$. 
[42] Sacré, C., Moisselin, J.M., Sabre, M., Flori, J.P., Dubuisson, B.. A new statistical approach to extreme wind speeds in france. J Wind Eng Ind Aerod 2007;95(9-11):1415-1423. doi:10.1016/j.jweia.2007.02 .013.

[43] de Wit, A.J.W., Van der Heijden, T.G.C., Thunnissen, H.A.M.. Vervaardiging en nauwkeurigheid van het LGN3-grondgebruiksbestand. Tech. Rep.; DLO-Staring Centrum; Wageningen; 1999. In Dutch.

[44] Yoon, J.J., Shim, J.S., Park, K.S., Lee, J.C.. Numerical experiments of storm winds, surges, and waves on the southern coast of Korea during Typhoon Sanba: the role of revising wind force. Nat Hazards Earth Sys Sci 2014;14(12):3279-3295. doi:10.5194/nhess-14-3279-2014.

[45] Lettau, H.H.. Note on the aerodynamic roughness-parameter estimation on the basis of roughness-element description. J Appl Meteorol 1969;8(5):828 832.

[46] Claassen, H.C., Riggs, A.C.. An estimate of the roughness length and displacement height of Sonoran Desert vegetation, South-Central Arizona. U.S. Geological Survey. Tech. Rep.; Water-Resources Investigations Report 92-4065, Denver, Colorado; 1993.

[47] Stanhill, G.. A simple instrument for the field measurement of a turbulent diffusion flux. J Appl Meteorol 1969;8(4):509-513.

[48] Blumberg, D.G., Greeley, R.. Field studies of aerodynamic roughness length. J Arid Environ 1993;25:39-48.

[49] DeBruin, H.A.R., Moore, C.J.. Zero-plane displacement and roughness length for tall vegetation, derived from a simple mass conservation hypothesis. Bound-Lay Meteorol 1985;31(1):39-49.

[50] Hicks, B.B., Hyson, P., Moore, C.J.. A study of eddy fluxed over a forest. J Appl Meteorol 1975;14(1):58-66.

[51] Parlange, M.B., Brutsaert, W.. Regional roughness of the landes forest and surface shear stress under neutral conditions. Bound-Lay Meteorol 1989;48(1-2):69-81. doi:10.1007/BF00121783. 
[52] Thom, A.S.. Momentum absorption by vegetation. Q J Roy Meteorol Soc 1971;97(414):414-428.

[53] Thom, A.S.. Momentum, mass and heat exchange of vegetation. Q J Roy Meteorol Soc 1972;98(415):124-134.

[54] Takagi, K., Miyata, A., Harazono, Y., Ota, N., Komine, M., Yoshimoto, M.. An alternative approach to determining zero-plane displacement, and its application to a lotus paddy field. Agr Forest Meteorol 2003;115:173181.

[55] Kimura, R., Kondo, J.. Heat balance model over a vegetated area and its application to a paddy field. J Meteorol Soc Jpn Ser II 1998;76(6):937-953.

[56] Davenport, A.G.. The dependence of wind loads on meteorological parameters. In: Conference on Wind Loads on Buildings. Toronto: University of Toronto Press; 1967,Paper 2.

[57] Hurtalová, T., Matejka, F.. Surface characteristics and energy fluxes above different plant canopies. Agr Forest Meteorol 1999;98-99:491-500. doi:10.1016/S0168-1923(99)00118-5.

[58] ESDU, . Characteristics of wind speed in the lower layers of the atmosphere near the ground: Strong winds (neutral atmosphere). Tech. Rep.; Engineering Sciences Data Unit; Regent Street, London, UK; 1972.

[59] Monteith, J.L., Unsworth, M.H.. Principles of Environmental Physics. Edward Arnold, LTD, New York, 291 pp.; 1990.

[60] Tieleman, H.W.. Roughness estimation for wind-load simulation experiments. J Wind Eng Ind Aerod 2003;91(9):1163-1173. doi:10.1016/ S0167-6105(03) 00058-8.

[61] MacArthur, C.D., Haines, P.A.. The roughness lengths associated with regions of heterogeneous vegetation and elevation. Tech. Rep. Contract DAAD7-8-D-0206; University of Dayton Research Institute; Dayton, OH $45469 ; 1982$. 
[62] Graefe, J.. Roughness layer corrections with emphasis on SVAT model applications. Agr Forest Meteorol 2004;124(3-4):237-251. doi:10.1016/j . agrformet. 2004.01 .003$.

[63] Dorman, J.L., Sellers, P.J.A.. Global climatology of albedo, roughness length and stomatal resistance for atmospheric general circulation models as represented by the simple biosphere model ( $\mathrm{SiB})$. J Appl Meteorol $1989 ; 28(9): 833-855$.

[64] Deacon, E.L.. Vertical Profiles of Mean Wind in the Surface Layers of the Atmosphere, Meteorol Off Geoph Mem 91. Tech. Rep.; Meteorological Office, United Kingdom; 1953.

[65] Brooks, F.A.. An Introduction to Physical Micrometeorology. University of California, Davis, California; 1959.

[66] Kalma, J.D., Fuchs, M.. Citrus orchards. In: Monteith, J.L., editor. Vegetation and the Atmophere. London: Academic Press; 1976,.

[67] Mochida, A., Murakami, S., Toshio-Ojima, , Kim, S., Ooka, R., Sugiyama, H.. CFD analysis of mesoscale climate in the greater tokyo area. J Wind Eng Ind Aerod 1997;67-68:459-477. doi:10.1016/s0167-6105(97) 00060-3

[68] Randall, J.M.. Wind profiles in an orchard plantation. Agr Forest Meteorol $1969 ; 6(6): 439-452$.

[69] Villalobos, F.J., Orgaz, F., Testi, L., Fereres, E.. Measurement and modeling of evapotranspiration of olive (Olea europaea L.) orchards. Eur J Agron 2000;13(2-3):155-163. doi:10.1016/s1161-0301(00)00071-x.

[70] Riou, C., Pieri, P., Valancogne, C.. Variation de la vitesse du vent à l'intérieur et au-dessus d'une vigne. Agr Forest Meteorol 1987;39:143-154. In French.

[71] van den Hurk, B.J.J.M.. Sparse canopy parameterization for meteorological models. Ph.D. thesis; Dept. of Meteorology, WAU, Wageningen, The Netherlands; 1995. 
[72] Weiss, A., Allen, L.H.. Vertical and horizontal air flow above rows of a vineyard. Agr Meteorol 1976;17(6):433-452. doi:10.1016/0002-1571(76) 90021-2.

[73] Garratt, J.R.. Surface influence upon vertical profiles in the atmospheric near-surface layer. Q J Roy Meteorol Soc 1980;106(450):803-819. doi:10. 1002/qj . 49710645011.PB.

[74] Grimmond, C.S.B., Oke, T.R.. Aerodynamic properties of urban areas derived from analysis of surface form. J Appl Meteorol 1999;38(9):12621292.

[75] Su, Z., Schmugge, T., Kustas, W.P., Massman, W.J.. An evaluation of two models for estimation of the roughness height for heat transfer between the land surface and the atmosphere. J Appl Meteorol 2001;40(11):19331951.

[76] Su, Z.. An introduction to the surface energy balance system (SEBS). Lecture notes, ESA TIGER Capacity Building Facility 1st Training Course on Advanced optical remote sensing; 2006.

[77] Wieringa, J.. Updating the Davenport roughness classification. J Wind Eng Ind Aerod 1992;41(1-3):357-368. doi:10.1016/0167-6105(92) 90434-C.

[78] Hanna, S.R., Chang, J.C.. Boundary layer parameterizations for applied dispersion modeling over urban areas. Bound-Lay Meteorol 1992;58(3):229259. doi:10.1007/BF02033826.

[79] Taylor, P.A.. Comments and further analysis on effective roughness lengths for use in numerical three-dimensional models. Bound-Lay Meteorol 1987;39:403-418.

[80] Schmid, H.P., Bunzli, B.. The influence of surface texture on the effective roughness length. Q J Roy Meteorol Soc 1995;121(521):1-21. doi:10.1002/ qj. 49712152102.

[81] Millward-Hopkins, J.T., Tomlin, A.S., Ma, L., Ingham, D., Pourkashanian, M.. Estimating aerodynamic parameters of urban-like surfaces with 
heterogeneous building heights. Bound-Lay Meteorol 2011;141(3):443-465. doi:10.1007/s10546-011-9640-2.

[82] Nakai, T., Sumida, A., Daikoku, K., Matsumoto, K., van der Molen, M.K., Kodama, Y., et al. Parameterisation of aerodynamic roughness over boreal, cool- and warm-temperate forests. Agr Forest Meteorol 2008;148(12):1916-1925. doi:10.1016/j .agrformet. 2008.03.009.

[83] Yang, R., Friedl, M.A.. Determination of roughness lengths for heat and momentum over boreal forests. Bound-Lay Meteorol 2003;107(3):581-603. doi:10.1023/a:1022880530523.

[84] Bengtsson, L., Andrae, U., Aspelien, T., Batrak, Y., Calvo, J., de Rooy, $\mathrm{W}$., et al. The harmonie-arome model configuration in the aladin-hirlam nwp system. Monthly Weather Review 2017;145(5):1919-1935.

[85] Seity, Y., Brousseau, P., Malardel, S., Hello, G., Bénard, P., Bouttier, F., et al. The AROME-France Convective-Scale Operational Model. Mon Weather Rev 2011;139:976-991. doi:10.1175/2010MWR3425.1.

[86] Navascués, B., Calvo, J., Morales, G., Santos, C., Callado, A., Cansado, A., et al. Long-term verification of HIRLAM and ECMWF forecasts over southern europe: History and perspectives of numerical weather prediction at AEMET. Atmos Res 2013;125-126(0):20-33. doi:10 .1016/j . atmosres . 2013.01.010.

[87] Ferragut, L., Montenegro, R., Montero, G., Rodríguez, E., Asensio, M.I., Escobar, J.M.. Comparison between 2.5-D and 3-D realistic models for wind field adjustment. J Wind Eng Ind Aerod 2010;98(10-11):548-558. doi:10.1016/j.jweia.2010.04.004.

[88] Zilitinkevich, S.S., Esau, I.N.. On integral measures of the neutral barotropic planetary boundary layer. Bound-Lay Meteorol 2002;104:371379 .

[89] Storn, R., Price, K.. Differential Evolution - A Simple and Efficient Heuristic for Global Optimization over Continuous Spaces. J Global Optim 1997;11(4):341-359. doi:10.1023/a:1008202821328. 
[90] Greiner, D., Emperador, J.M., Winter, G.. Single and multiobjective frame optimization by evolutionary algorithms and the auto-adaptive rebirth operator. Comput Methods Appl Mech Engrg 2004;193(33-35):37113743. doi:10.1016/j.cma.2004.02.001.

[91] Byrd, R.H., Lu, P., Nocedal, J., Zhu, C.. A limited memory algorithm for bound constrained optimization. SIAM J Sci Comput 1995;16(5):11901208. doi:10.1137/0916069.

[92] Montenegro, R., Cascón, J.M., Escobar, J.M., Rodríguez, E., Montero, G.. An automatic strategy for adaptive tetrahedral mesh generation. Appl Numer Math 2009;59(9):2203-2217. doi:10.1016/j . apnum.2008 .12 .010.

[93] Cascón, J.M., Rodríguez, E., Escobar, J.M., Montenegro, R.. Comparison of the Meccano method with standard mesh generation techniques. Engineering with Computers 2013;:1-14doi:10.1007/s00366-013-0338-6.

[94] Zilitinkevich, S.S., Mammarella, I., Baklanov, A.A., Joffre, S.M.. The effect of stratification on the aerodynamic roughness length and displacement height. Bound-Lay Meteorol 2008;129:179-190. doi:10.1007/ s10546-008-9307-9.

[95] Quarteroni, A., Manzoni, A., Negri, F.. Reduced Basis Methods for Partial Differential Equations. An Introduction. Switzerland: Springer; 2016.

[96] Cascón, J.M., Y, A.E., Ferragut, L., Hernández, E.. A reduced basis for a local high definition wind model. Computer Methods in Applied Mechanics and Engineering 2016;311:438-456. doi:10.1016/j.cma.2016.08.028.

[97] Miller, C., Gibbons, M., Beatty, K., Boissonnade, A.. Topographic speed-up effects and observed roof damage on bermuda following hurricane fabian (2003). Weather and Forecasting 2013;28(1):159-174. doi:10.1175/ WAF-D-12-00050.1. 